\title{
Efecto de la exclusión de hormigas sobre la abundancia y diversidad de Hymenoptera Parasitica en un cultivo ecológico de mandarinos (La Selva del Camp, Tarragona, España)
}

\author{
Carolina Bañol \\ Universidad Estatal de Milagro. Facultad Académica de Ciencias de la Ingeniería \\ Ciudadela Universitaria, km 1,5 vía Milagro km 26. Milagro. Guayas (Ecuador) \\ cbanolp@unemi.edu.ec
}

\section{José Antonio Barrientos}

Universitat Autònoma de Barcelona. Unitat de Zoologia

Facultat de Biociències. 08193 Bellaterra

joseantonio.barrientos@uab.es

\section{Josep Piñol}

Universitat Autònoma de Barcelona. CREAF. Unitat d'Ecologia

Facultat de Biociències. 08193 Bellaterra

josep.pinol@uab.es

Fecha de recepción: 16 de junio de 2014

Fecha de aceptación: 9 de febrero de 2015

Fecha de publicación: 18 de mayo de 2015

\section{Resumen}

Los Hymenoptera Parasitica son uno de los mayores grupos controladores de insectos plaga en cultivos agrícolas. Presentamos aquí un estudio de cinco años en el que se describe la abundancia y la diversidad de especies parasitoides asociadas a un cultivo ecológico de cítricos en La Selva del Camp (Tarragona, España) en función de un experimento de exclusión de hormigas de las copas de los árboles, puesto que se sabe que las hormigas suelen interaccionar negativamente con parasitoides y depredadores de plagas. Nuestros resultados muestran que existe una gran diversidad de parasitoides asociada a los cítricos. Pteromalidae, Encyrtidae y Scelionidae son las familias dominantes; todas ellas experimentaron cambios significativos durante el periodo de estudio. Además, la exclusión de hormigas tuvo un efecto positivo en la abundancia general de los parasitoides, de modo que las poblaciones fueron más abundantes a partir del año 2006 y aumentaron en los años siguientes.

Palabras clave: control biológico; Citrus; exclusión; agricultura orgánica; parasitoides; plagas. 
Abstract. Effect of ant exclusion on the abundance and diversity of Hymenoptera Parasitica in an organic citrus grove (La Selva del Camp, Tarragona, Spain)

Parasitic Hymenoptera are one of the most diverse and abundant insects and play an important role in limiting pest populations in agricultural crops. We carried out a five-year study on the number and diversity of parasitoid species associated with an organic citrus grove in Tarragona (Spain) to establish the effect of ant exclusion from tree canopies. Our results showed that there is a large diversity of parasitoids associated with phytophagous insects in citrus. Pteromalidae, Encyrtidae and Scelionidae were the most dominant families. Ant exclusion had a positive effect on the abundance of parasitoids, whose populations were more abundant from 2006 and increased in the following years.

Keywords: Biological control; Citrus; exclusion; organic agriculture; parasitoids; pest.

\section{Introducción}

El orden Hymenoptera es uno de los grupos más diversos y abundantes de insectos (Gauld y Bolton, 1988; Goulet y Huber, 1993). Cuenta con 83 familias (Fernández y Sharkey, 2006) y más de 120.000 especies a nivel mundial, muchas de las cuales tienen una gran importancia económica, como es el caso de los parasitoides (Lasalle y Gauld, 1993; Sharkey, 2007). En España, este orden cuenta aproximadamente con 9.800 especies que corresponden al 5\% del total de himenópteros en el mundo (Martín-Piera y Lobo, 2000). El suborden Apocrita comprende los Hymenoptera Parasitica, que incluyen 11 superfamilias, 48 familias y más de 50.000 especies a nivel mundial (Anento y Selfa, 1997; Hagler, 2000; Zuparko, 2008) y son algunos de los más abundantes enemigos naturales de plagas (Gordh et al., 1999; Viggiani, 2000). Estos himenópteros se denominan parasitoides. La hembra parasitoide adulta oviposita en el cuerpo del hospedador. Su descendencia, en su fase larvaria, vive y se alimenta de él hasta causarle la muerte. A continuación, se originan los adultos de vida libre (Askew, 1971; Godfray, 1994; Jacas et al., 2008). A menudo, estas especies se consideran reguladoras del equilibrio de los ecosistemas, por cuanto controlan las poblaciones de insectos, principalmente las especies plaga cuando son sus hospedadores. Los parasitoides desempeñan también un papel importante en los ecosistemas, por lo que son bioindicadores de la diversidad de artrópodos fitófagos a los que atacan (Sharkey, 2007).

De una manera natural, los insectos fitófagos están sometidos a un control de sus poblaciones mediante sus enemigos naturales, entre los que se encuentran depredadores, parasitoides y agentes patógenos como hongos, virus y bacterias (Avilla, 2005; Belliure et al., 2008). Todos estos controladores son muy efectivos, pero dependen del número de plagas y de su capacidad de reproducción. En consecuencia, la dinámica poblacional de estos enemigos naturales actúa de forma dependiente de la densidad, y sus fluctuaciones constituyen la base del control natural (Albajes y Alomar, 2008).

Los insectos plaga más comunes encontrados en el cultivo de cítricos son Ceroplastes sinensis Del Guercio, 1900 (Coccoidea: Coccidae), Saissetia oleae 
Olivier, 1791 (Coccoidea: Coccidae), Icerya purchasi Maskell, 1878 (Coccoidea: Margarodidae), Phyllocnistis citrella Stainton, 1856 (Lepidoptera: Gracillaridae), Ceratitis capitata Wiedemann, 1824 (Diptera: Tephritidae), y los pulgones Aphis spiraecola Patch, 1914, A. gossypii Glover, 1877 y Toxoptera aurantii Bayer de Foscolombe, 1841.

En este trabajo, nos hemos centrado en el conocimiento de los Hymenoptera Parasitica, que son de gran trascendencia para el control biológico de plagas en cultivos de frutales y otros tipos (Viggiani, 2000; Hajek, 2004; Jacas et al., 2008). Los parasitoides poseen una gran diversidad de especies. Su presencia o ausencia depende del tipo de agroecosistema de que se trate y de las características biológicas y ecológicas de sus hospedadores (Sullivan y Völkl, 1999). Hay dos superfamilias que agrupan el mayor número de parasitoides, los Chalcidoidea y los Ichneumonoidea, cuyas especies son muy utilizadas en programas de control biológico (Pina, 2008). Para los cítricos en España, algunas de las especies de parasitoides más estudiadas son: Citrostichus phyllocnistoides Narayanan, 1960 (Eulophidae), que actúa sobre el minador de las hojas de los cítricos Phyllocnistis citrella Stainton, 1856 (Lepidoptera: Gracillariidae) (Garcia-Marí et al., 2004), Encarsia herndoni Girault, 1933 (Aphelinidae) sobre la cochinilla cornafina Insulaspis gloverii Packard, 1869 (Hemiptera: Diaspididae) (Verdú, 1985). Soler et al. (2002) menciona que Cales noacki Howard, 1907 (Aphelinidae) actúa sobre la mosca blanca algodonosa (Aleurothrixus floccosus Maskell, 1896) y que Eretmocerus sp. ataca la mosca blanca japonesa Parabemisia myricae Kuwana, 1927 (Garcia-Marí et al., 1996). Los parasitoides Aphytis melinus De Bach, 1959 y A. lingnanensis Compere, 1955 se desarrollan sobre cochinillas (Hemiptera: Diaspididae), que son predominantes en cítricos de Andalucía y Valencia (Urbaneja et al., 2008), y Metaphycus sp. (Encyrtidae) controla las poblaciones de Coccidae (Soler et al., 2002).

Los parasitoides de mayor importancia sobre pulgones en plantaciones de cítricos han sido Lysiphlebus testaceipes Cresson, 1880 (Braconidae) sobre las especies Aphis spiraecola Patch, 1914, Aphis gossypii Glover, 1877, A. fabae Scopoli, 1763, Myzus persicae Sulzer, 1776 y Toxoptera aurantii Boyer de Fonscolombe, 1841; también Lysiphlebus confusus Tremblay y Eady, 1978, Lysiphlebus fabarum Marshall, 1896, Trioxis angelicae Haliday, 1833, Aphidius matricariae Haliday, 1912, y Praon volucre Haliday, 1833 (todos Braconidae), este último principalmente sobre Toxoptera aurantii Boyer de Fonscolombe, 1841 (Michelena et al., 1994; Hermoso de Mendoza et al., 2012).

Se suele considerar que los cultivos ecológicos favorecen una mayor biodiversidad que sus homólogos convencionales. Así la riqueza de especies de artrópodos fitófagos, depredadores y parasitoides se incrementan con esta modalidad, sin embargo, esto depende de la respuesta de los grupos taxonómicos (Hole et al., 2005). En los cítricos se han mencionado 875 especies de artrópodos fitófagos en todo el mundo (Ebeling, 1959), aunque en España, Garrido Torres \& Ventura (1993) solo citan aproximadamente 80 especies, lo que representa el $9 \%$ de todos los fitófagos que se han mencionado en los cítricos en el mundo (Soler et al., 2002). 
Como se ha mencionado anteriormente, una de las plagas más comunes en cítricos son los pulgones, los cuales se consideran plagas ocasionales capaces de causar cierto daño a los árboles, como la disminución en el crecimiento de los brotes infestados, la detención del desarrollo foliar o la posibilidad de caída de flores y frutos jóvenes (Barbagallo et al., 1998). Los pulgones más importantes son: Aphis spiraecola, A. gossypii, Toxoptera aurantii, Aphis craccivora Koch, 1854, A. fabae, Macrosiphum euphorbiae Thomas, 1878 y Myzus persicae, que son atacados principalmente por bracónidos de la subfamilia Aphidiinae; éstos últimos cuentan con más de 400 especies en el mundo y se consideran endoparasitoides específicos de pulgones (Starý, 1970; Hermoso de Mendoza et al., 1997; Michelena et al., 2004). Entre ellos, destacan Lysiphlebus testaceipes, Trioxys angelicae, Praon volucre (Llorens, 1990; Michelena y Sanchis, 1997). También se encuentran asociados a los cítricos otros hiperparasitoides, principalmente los pteromálidos, que agrupan aproximadamente a 3.100 especies conocidas, repartidas en 600 géneros a nivel mundial (Gauld y Bolton, 1988; Gaston, 1993); los más importantes son de los géneros Asaphes Walker, 1834 y Pachyneuron Walker, 1833 (Graham, 1969).

Por otra parte, es bien conocida la asociación que existe entre las hormigas y algunos insectos plaga, principalmente los pulgones. Las hormigas se alimentan de la melaza producida por estos y, a cambio, ellas les ofrecen protección en contra de los depredadores y parasitoides (Way, 1963; Völkl, 1997; Müller y Godfray, 1999). Las hormigas pueden limitar la eficacia de los parasitoides evitando el acceso a las colonias de áfidos y algunas veces matando a los invasores (Völkl, 1997). También la presencia de algunas hormigas reduce significativamente la acción de los hiperparasitoides o parasitoides secundarios, con lo cual proporcionan un espacio libre de enemigos al parasitoide primario (Novak, 1994; Völkl, 1997). Igualmente, la presencia de hormigas reduce el número de depredadores en las colonias de pulgones (Kaneko, 2003a).

El presente estudio se centra en dar a conocer la diversidad de los Hymenoptera Parasitica de un cultivo ecológico de cítricos a lo largo de cinco años y en determinar el efecto de la exclusión de hormigas en los árboles sobre estas comunidades.

\section{Materiales y métodos}

\section{Zona de estudio}

La zona de estudio es una plantación de cítricos en La Selva del Camp (Tarragona, noreste de España; $41^{\circ} 13^{\prime} 07^{\prime}$ ' $\mathrm{N}, 1^{\circ} 08^{\prime} 35^{\prime}$ ' E). Normalmente, el clima es mediterráneo, con una primavera lluviosa, un otoño igualmente lluvioso, un verano seco y un invierno cálido acompañado de olas de frío. La plantación consta de aproximadamente 300 árboles de clementina (Citrus clementina var. clemenules) injertados sobre patrón híbrido citrange Carrizo (Poncirus trifoliata (L.) Raf. $\times$ Citrus sinensis (L.) Osb.). El cultivo cumple con todas las normas de la agricultura ecológica desde 2004 (es decir, ausencia de pesticidas, fungicidas o herbicidas, y sólo aplicación de abono orgánico utilizado como fertilizante). El sistema 
de riego del cultivo al iniciar el estudio consistió en riego por goteo localizado, pero, en el año 2006, se cambió por el método de microaspersión.

\section{Muestreo de parasitoides}

Fueron seleccionados al azar dieciséis árboles dentro de la parcela del cultivo, ocho árboles control para el acceso libre de insectos y ocho árboles con exclusión, en los que se evitó que las hormigas y otros insectos caminadores pudieran acceder a las copas a través del tronco. Estos tratamientos se establecieron en enero de 2004 y, posteriormente, los árboles fueron muestreados con una frecuencia mensual. El muestreo consistió en el método de batido de las copas de los árboles con tres golpes secos en los lados opuestos de los mismos. Una rápida actuación in situ hizo posible la captura, mediante aspirador entomológico, de los artrópodos caídos sobre un paraguas japonés (una tela blanca de $0,5 \mathrm{~m}^{2}$ ), que fueron inmediatamente preservados en etanol al 70\%. Estos experimentos se repitieron durante 5 años (2004-2008), utilizando un grupo de árboles diferente cada año.

\section{Exclusión de hormigas}

Para impedir el paso de los insectos caminadores hacia las copas de los árboles, se aplicó una barrera pegajosa en los troncos de cada árbol de exclusión. Esta barrera está hecha a base de polibuteno (Rata Stop®) aplicada sobre un plástico alimentario encima de un cilindro de guata sobre el tronco, según método de Samways y Tate (1985). Las fechas y el método de muestreo fueron los mismos que se usaron en los árboles control durante los cinco años de estudio.

\section{Clasificación de las muestras de parasitoides}

Una vez en el laboratorio, los parasitoides fueron separados de los demás grupos de artrópodos colectados y se contabilizaron e identificaron, siguiendo la metodología tradicional, mediante una lupa binocular y utilizando diferentes claves de carácter general [(Ceballos, 1964; Goulet y Huber, 1993; Sharkey, 2007) o especializada, para Chalcidoidea (Askew, 1975; Boucek y Rasplus, 1991) y para Cynipoidea (Fergusson, 1986; Nieves-Aldrey, 2001)]. Conviene dejar constancia de que los parasitoides son diminutos, de difícil manipulación y su identificación entraña un alto grado de especialización, por lo que se ha recurrido al asesoramiento por parte de especialistas en la taxonomía del grupo, principalmente Antoni Ribes, a quien se ha confiado el grueso del material recolectado. A pesar de ello, 58 especímenes no se han podido identificar con la suficiente precisión. Así pues, podemos decir que, si bien la identificación a nivel genérico es segura (a excepción de un solo ejemplar de Pteromalidae), la identidad específica está sujeta a una prudente provisionalidad, por ello sólo se explicita en aquellos casos que la consideramos correcta. 


\section{Análisis estadístico}

Para ofrecer un conocimiento de la composición y de la variación temporal de la comunidad de parasitoides, hemos tenido en consideración sólo los árboles control; de este modo, los resultados ofrecidos son susceptibles de ser utilizados como elemento comparativo de los efectos de la exclusión.

En primer lugar, se comparó la comunidad de parasitoides entre los cinco años estudiados en los árboles control mediante un análisis de la varianza multivariante permutacional (ANOSIM) previa transformación (raíz cuadrada de los datos) y usando el índice de Bray-Curtis para calcular la similitud entre árboles. Después, se analizaron las diferencias para el conjunto de la comunidad de parasitoides entre los árboles control y los árboles con exclusión de hormigas para cada año de estudio, utilizando también un ANOSIM previa transformación (raíz cuadrada de los datos) con el índice de Bray-Curtis. La variable respuesta fue la media del número de individuos de cada especie de cada árbol, desde febrero hasta diciembre de cada año estudiado (no se incluyó el mes de enero, porque los tratamientos «control/exclusión de hormigas» se establecían en ese momento). Para los años en los que el análisis anterior mostró diferencias significativas entre tratamientos, se realizó un análisis de porcentaje de similitudes (SIMPER), con el fin de calcular la contribución de cada especie a la disimilaridad global entre tratamientos. A continuación, se seleccionaron los primeros taxones de la lista de SIMPER (las especies con resultados más distintos entre tratamientos) y se testó si su abundancia era efectivamente distinta utilizando ANOSIM, previa transformación (raíz cuadrada) y usando en este caso la distancia euclidea como medida de disimilaridad. El análisis multivariante (ANOSIM) y el porcentaje de similitudes (SIMPER) fueron realizados mediante el programa PRIMER v6 (Clarke y Gorley, 2006).

\section{Resultados}

\section{Comunidad de parasitoides (árboles control)}

Se recolectaron un total de 4.026 parasitoides, cuya identidad taxonómica se detalla en el anexo. En él, y siguiendo las recomendaciones de Antoni Ribes, sólo se explicitan los nombres genéricos de las especies encontradas (a excepción de aquellas que son principales y nos brindan una seguridad taxonómica razonable); de este modo, facilitamos el desarrollo del estudio del material que dicho autor tiene en curso. En los árboles control, se contaron 1.483 individuos en los cinco años de estudio, el resto (2.543) se colectaron en árboles con exclusión.

Atendiendo a los datos obtenidos en los árboles control, las superfamilias más abundantes para estos árboles fueron los Chalcidoidea (58\% del total de individuos), los Platygastroidea (el 23\%) y los Ichneumonoidea (el 13\%). El 6\% restante correspondió a unos pocos individuos de las superfamilias Cynipoidea, Ceraphronoidea, Chrysidoidea y Proctotrupoidea (tabla 1). Los Chalcidoidea más abundantes pertenecieron a las familias Pteromalidae (el 67\% del total de Chalcidoidea), Encyrtidae (18\%) y Eulophidae (el 11\%) (figura 1A, tabla 1). Las especies principales de la familia Pteromalidae fueron Pachyneuron formosum Walker, 
Tabla 1. Número total de individuos de las superfamilias y familias encontradas en los cinco años de muestreo en ambos tratamientos. Entre paréntesis, después del nombre de la familia se indica el número de géneros y especies de la misma

\begin{tabular}{|c|c|c|c|c|}
\hline Superfamilias & Familias & Control & Exclusión & Total \\
\hline \multirow[t]{3}{*}{ Ceraphronoidea } & Ceraphronidae ( 3 géneros, 6 especies) & 19 & 28 & 47 \\
\hline & Megaspilidae ( 3 géneros, 10 especies) & 7 & 21 & 28 \\
\hline & & 26 & 49 & 75 \\
\hline \multirow[t]{14}{*}{ Chalcidoidea } & Aphelinidae ( 3 géneros, 8 especies) & 8 & 12 & 20 \\
\hline & Chalcididae ( 3 géneros, 5 especies) & 1 & 11 & 12 \\
\hline & Encyrtidae (19 géneros, 34 especies) & 156 & 282 & 438 \\
\hline & Eulophidae (18 géneros, 36 especies) & 92 & 121 & 213 \\
\hline & Eupelmidae (1 género, 1 especies) & 10 & 8 & 18 \\
\hline & Eurytomidae ( 3 géneros, 4 especies) & 7 & 6 & 13 \\
\hline & Mymaridae (2 géneros, 2 especies) & 5 & 1 & 6 \\
\hline & Perilampidae (1 género, 3 especies) & 1 & 5 & 6 \\
\hline & Pteromalidae (26 géneros, 42 especies) & 570 & 1214 & 1784 \\
\hline & Signiphoridae (1 géneros, 1 especie) & 1 & 1 & 2 \\
\hline & Tetracampidae (1 género, 1 especie) & 1 & 3 & 4 \\
\hline & Torymidae (4 géneros, 4 especies) & 3 & 3 & 6 \\
\hline & Trichogrammatidae (1 género, 1 especie) & 0 & 1 & 1 \\
\hline & & 855 & 1668 & 2523 \\
\hline \multirow[t]{4}{*}{ Chrysidoidea } & Bethylidae (1 género, 2 especies) & 12 & 9 & 21 \\
\hline & Chrysididae (1 género, 1 especie) & 2 & 2 & 4 \\
\hline & Dryinidae (1 género, 1 especie) & 0 & 1 & 1 \\
\hline & & 14 & 12 & 26 \\
\hline \multirow[t]{3}{*}{ Cynipoidea } & Cynipidae (2 géneros, 2 especies) & 1 & 2 & 3 \\
\hline & Figitidae (9 géneros, 13 especies) & 39 & 52 & 91 \\
\hline & & 40 & 54 & 94 \\
\hline \multirow[t]{3}{*}{ Ichneumonoidea } & Braconidae (26 géneros, 36 especies) & 118 & 131 & 249 \\
\hline & Ichneumonidae ( 24 géneros, 32 especies) & 74 & 93 & 167 \\
\hline & & 192 & 224 & 416 \\
\hline \multirow[t]{3}{*}{ Platygastroidea } & Platygastridae (5 géneros, 5 especies) & 54 & 56 & 110 \\
\hline & Scelionidae (5 géneros, 22 especies) & 292 & 463 & 755 \\
\hline & & 346 & 519 & 865 \\
\hline \multirow[t]{3}{*}{ Proctotrupoidea } & Diapriidae (5 géneros, 7 especies) & 9 & 16 & 25 \\
\hline & Proctotrupidae (1 género, 1 especies) & 1 & 1 & 2 \\
\hline & & 10 & 17 & 27 \\
\hline \multicolumn{2}{|c|}{ Total de individuos } & 1483 & 2543 & 4026 \\
\hline
\end{tabular}



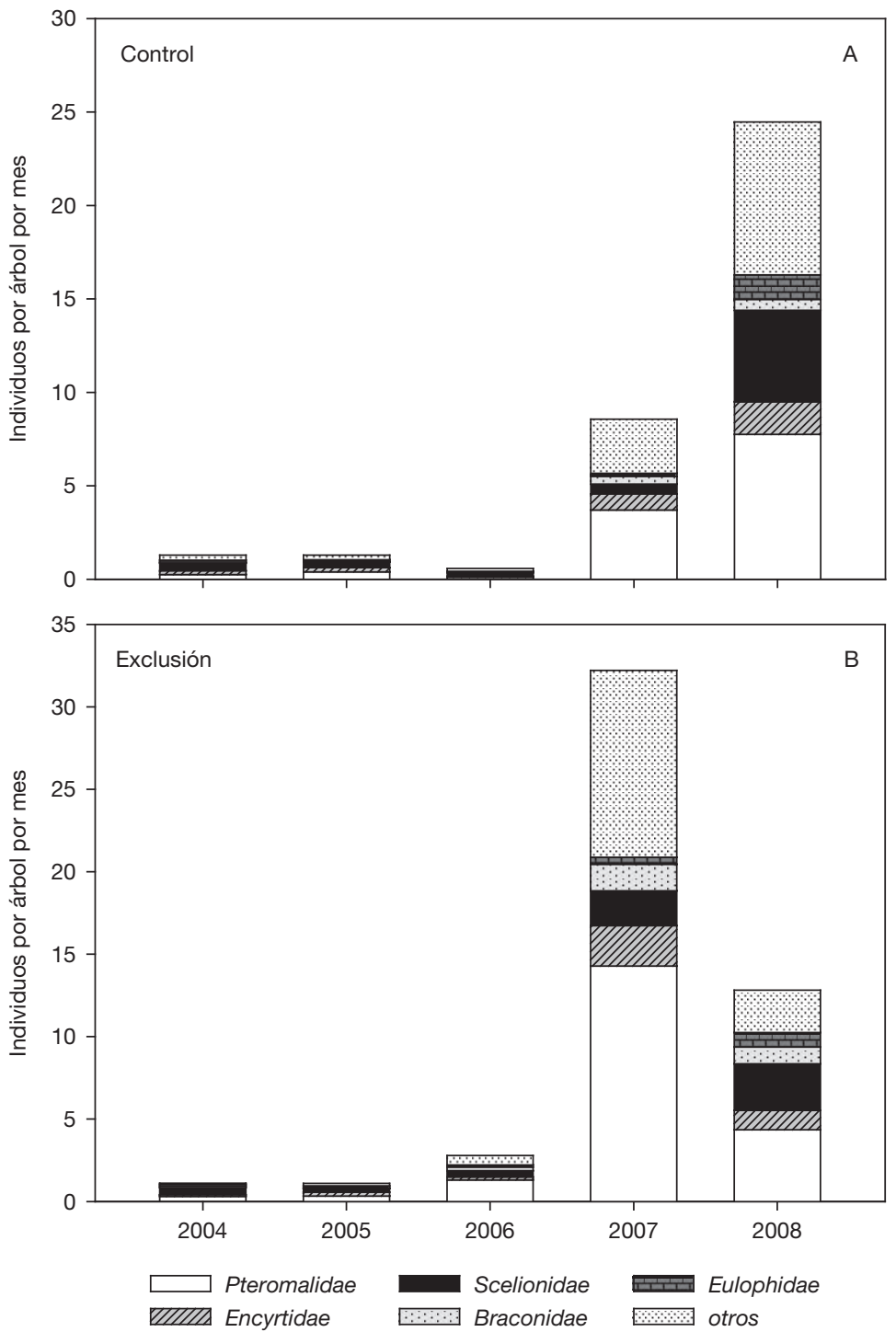

Figura 1. Variación temporal de las principales familias de Hymenoptera Parasitica en los cinco años de estudio. A: total de individuos en árboles control. B: total de individuos en árboles con exclusión. 

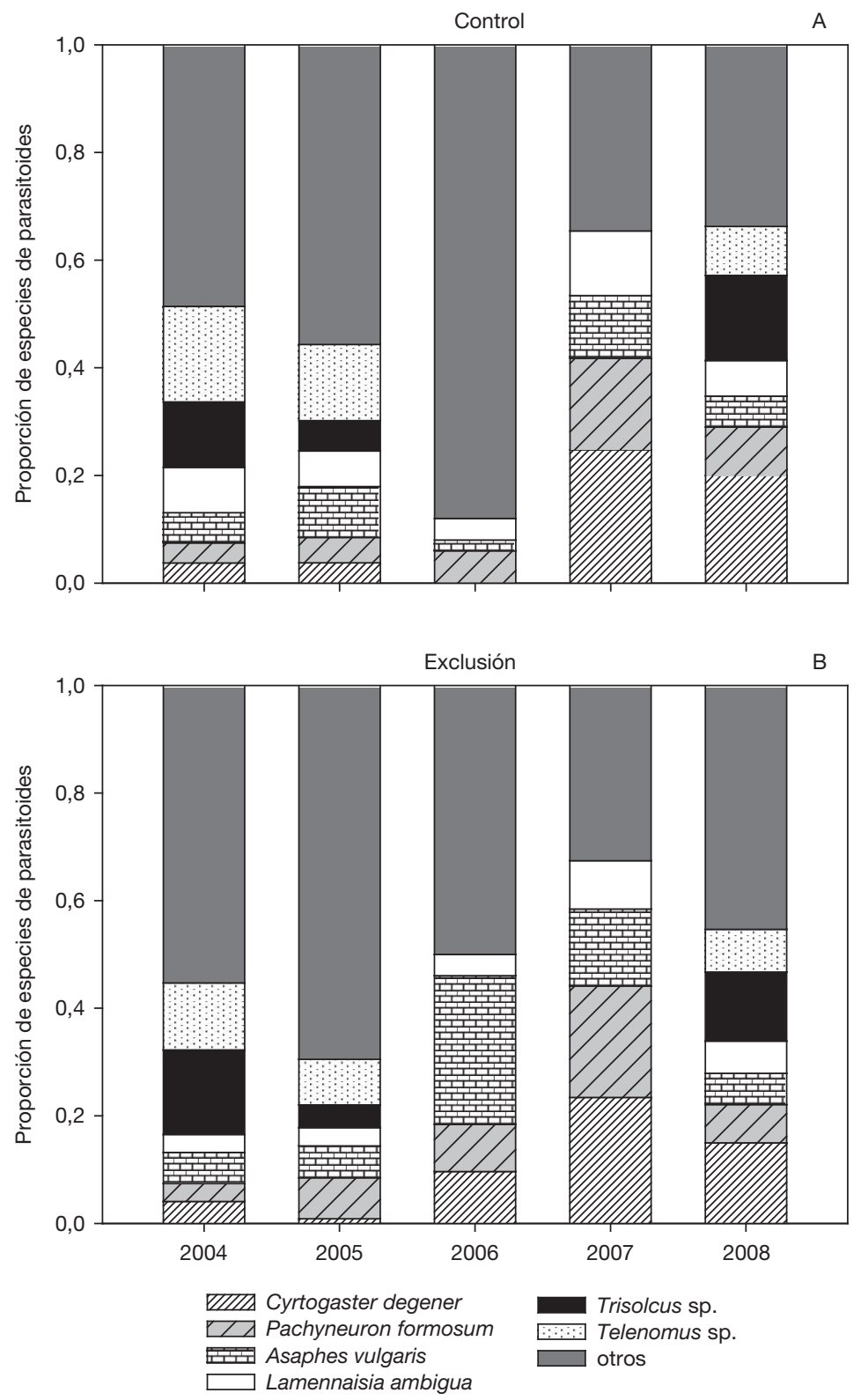

Figura 2. Proporción de los taxones más abundantes de parasitoides desde el año 2004 hasta el año 2008. A: en árboles control. B: en árboles con exclusión. 
1833 (el 32\% de los pteromálidos), Asaphes vulgaris Walker, 1834 (el 30\%) y Cyrtogaster degener Walker, 1833 (el 21\%) (figura 2A). El encírtido más abundante fue Lamennaisia ambigua Nees, 1976 (el 46\% de los encírtidos). El 84\% de los Platygastroidea correspondieron a la familia Scelionidae, siendo Telenomus sp. (el 32\% de los Scelionidae) y Trissolcus sp. (el 29\%) los principales taxones (figura 2A). En la superfamilia Ichneumonoidea, el $61 \%$ de la muestra fueron Braconidae, siendo Blacus sp. (el 22\%) y Lysiphlebus testaceipes Cresson, 1880 (el 13\%) los taxones más abundantes. En la segunda familia más abundante, los Ichneumonidae (el 38\% de los Ichneumonoidea, tabla 1), destacó por su abundancia Stenomacrus sp.1 (probablemente, Stenomacrus aff. affinitor Aubert, 1981; con el $55 \%$ de los Ichneumonidae).

\section{Variación interanual (árboles control)}

Al analizar los cambios de la comunidad de parasitoides a lo largo del tiempo en los árboles control, se han encontrado diferencias significativas entre años (2004 a 2008, $P=0,0002$, tabla 2). El análisis a posteriori entre años individuales mostró que todos ellos presentaron diferencias entre sí $(P<0,05)$, excepto entre los años 2004 y $2005(P=0,36)$.

Atendiendo a los árboles control, en los años 2004, 2005 y 2006, los parasitoides fueron poco abundantes, pero su población aumentó en los años siguientes. Durante el año 2007, los parasitoides fueron aumentando y, en el año 2008 (figura 3), llegaron a su pico máximo. El brusco incremento de parasitoides en los años 2007 y 2008 se puede atribuir, esencialmente, a dos familias, los Pteromalidae (el $46 \%$ de los individuos en el conjunto de 2007 y 2008) y los Scelionidae (el 20\% de los individuos de 2008) (figura 1A).

La abundancia de las especies principales también varía a lo largo del tiempo de estudio. En los años 2004 y 2005, se obtuvieron pocos individuos de Cyrtogas-

Tabla 2. Resultados del estadístico $R$ de ANOSIM y su significación estadística $(P)$ obtenidos en la comparación año a año para los árboles control a lo largo de los cinco años de estudio

\begin{tabular}{ccc}
\hline Años & $\boldsymbol{R}$ & $\boldsymbol{P}$ \\
\hline 2004,2005 & 0,022 & 0,36 \\
\hline 2004,2006 & 0,451 & 0,0002 \\
\hline 2004,2007 & 0,868 & 0,0002 \\
\hline 2004,2008 & 0,744 & 0,0002 \\
\hline 2005,2006 & 0,419 & 0,0002 \\
\hline 2005,2007 & 0,682 & 0,0002 \\
\hline 2005,2008 & 0,554 & 0,0002 \\
\hline 2006,2007 & 0,334 & 0,0002 \\
\hline 2006,2008 & 0,399 & 0,0002 \\
\hline 2007,2008 & 0,808 & 0,0002 \\
\hline
\end{tabular}




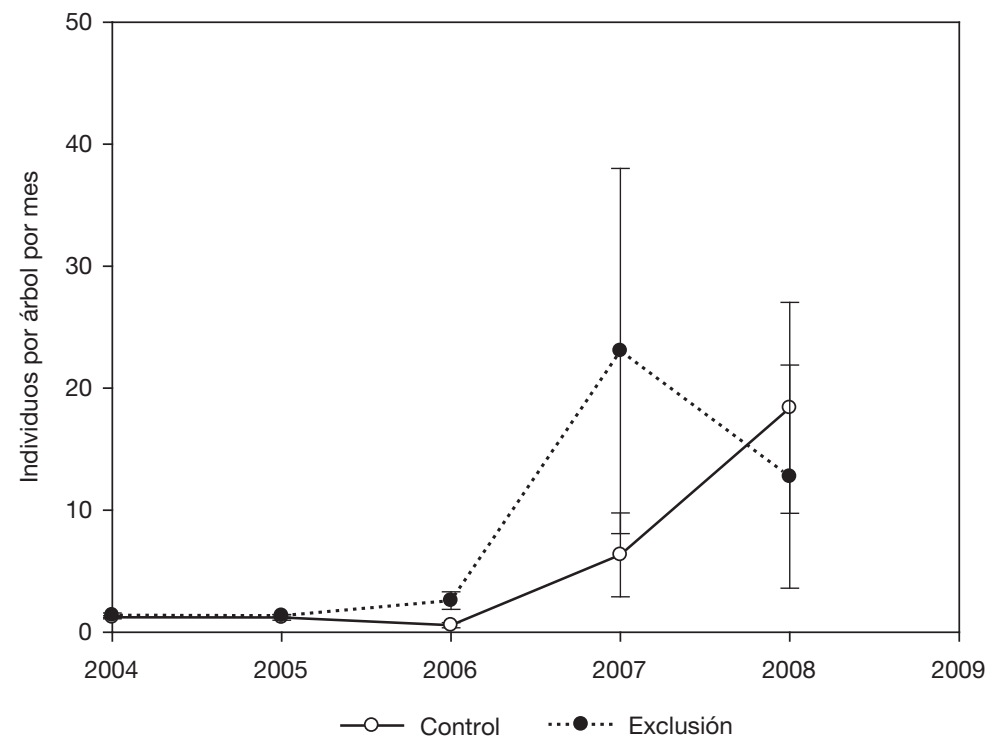

Figura 3. Variación temporal de la abundancia de parasitoides durante los cinco años de estudio. La gráfica representa el total de capturas en árboles control y en árboles con exclusión. Las barras indican el error estándar (EE).

ter degener y desaparecieron en su totalidad en el año 2006, pero en los dos últimos años reaparecieron como la especie más abundante (el $45 \%$ de los individuos en el conjunto de 2007 y 2008) (figura 2A).

Las especies Pachyneuron formosum, Lamennaisia ambigua y Asaphes vulgaris presentan su abundancia más baja en 2006, con un $2 \%$ del total de individuos. Estas especies incrementaron su población en 2007 y 2008. Trissolcus sp. y Telenemus sp. fueron abundantes en los dos primeros años, desaparecieron en 2006 y reaparecieron en 2008 (un $11 \%$ y un 16\%, respectivamente, figura 2A).

Tabla 3. Resultados del estadístico $R$ de ANOSIM y su significación estadística $(P)$ obtenidos para los cinco años de estudio entre los árboles control y los árboles con exclusión. Los años significativos aparecen en negrita

\begin{tabular}{ccc}
\hline Años & $\boldsymbol{R}$ & $\boldsymbol{P}$ \\
\hline 2004 & $-0,09$ & 0,85 \\
2005 & 0,004 & 0,45 \\
$\mathbf{2 0 0 6}$ & $\mathbf{0 , 1 8}$ & $\mathbf{0 , 0 0 8}$ \\
2007 & $-0,03$ & 0,59 \\
$\mathbf{2 0 0 8}$ & $\mathbf{0 , 3 8}$ & $\mathbf{0 , 0 0 5}$ \\
\hline
\end{tabular}




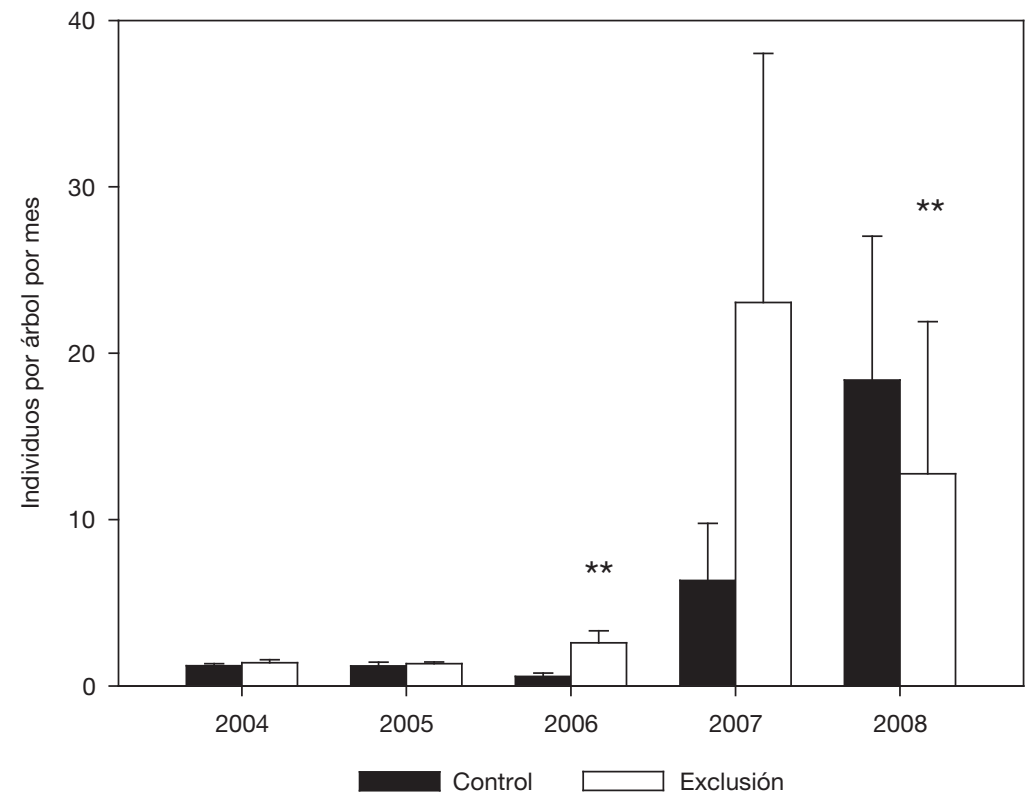

Figura 4. Comparación de la abundancia de parasitoides durante los cinco años de estudio en árboles control y en árboles con exclusión. La abundancia corresponde a la media del número de individuos en cada árbol desde febrero hasta diciembre de cada año. Las barras indican el error estándar (EE). Los asteriscos indican la significancia estadística de la media anual entre ambos tratamientos $(* P<0,05 ; * * P<0,01)$.

\section{Efecto de la exclusión de hormigas}

En los árboles excluidos de insectos caminadores, se capturaron 2.543 especímenes (tabla 1). Las superfamilias más abundantes fueron las mismas que en los árboles control Chalcidoidea (un 65\%), Platygastroidea (un 20\%) e Ichneumonoidea (un 9\%). Pteromalidae (un 73\%) fue la familia más abundante en los árboles con exclusión, especialmente en el año 2007 (figura 1B). Las especies más importantes de esta familia fueron Cyrtogaster degener (38\%), Pachyneuron formosum (26\%) y Asaphes vulgaris (24\%) (figura 2B).

En los primeros años, las poblaciones de parasitoides fueron muy bajas y sin diferencias entre tratamientos $(P=0,85$ en 2004 y $P=0,45$ en 2005; figura 4; tabla 3), pero los parasitoides aumentaron en los últimos años. En 2006 y 2008, las comunidades de parasitoides de los árboles control y de los árboles con exclusión fueron distintas (2006: $P=0,003$; 2008: $P=0,005$; figura 4; tabla 3); en 2007, la abundancia de parasitoides fue elevada, pero no se apreciaron diferencias significativas entre tratamientos $(P=0,59$, tabla 3$)$.

Las especies con diferencias en la abundancia entre tratamientos fueron Asaphes vulgaris $(P=0,0003)$ en el año 2006 (figura 5A, tabla 4) y Cyrtogaster 
Tabla 4. Resultados del análisis ANOSIM sobre las especies que difieren más entre tratamientos según SIMPER. Se muestra también la media de las abundancias $( \pm E E)$ dadas como el número de individuos en cada árbol de las especies más importantes de parasitoides de los años 2006 y 2008 entre tratamientos

\begin{tabular}{lcccc}
\hline \multicolumn{1}{c}{ Media $\pm \mathbf{E E}$} \\
\hline \multicolumn{1}{c}{ Especies } & $\boldsymbol{R}$ & $\boldsymbol{P}$ & Control & Exclusión \\
\hline Asaphes vulgaris (2006) & 0,86 & 0,0003 & $0,01 \pm 0,01$ & $0,72 \pm 0,35$ \\
\hline Cyrtogaster degener (2008) & 0,51 & 0,003 & $3,67 \pm 1,75$ & $1,91 \pm 1,87$ \\
\hline Trissolcus sp. (2008) & 0,31 & 0,008 & $2,91 \pm 1,39$ & $1,64 \pm 1,43$ \\
\hline Pachyneuron formosum (2008) & 0,52 & 0,004 & $1,66 \pm 0,84$ & $0,91 \pm 0,85$ \\
\hline Telenomus sp. (2008) & 0,27 & 0,032 & $1,67 \pm 0,8$ & $1,01 \pm 0,83$ \\
\hline
\end{tabular}

degener $(P=0,003)$, Pachyneuron formosum $(P=0,004)$, Trisolcus $\mathrm{sp} .(P=0,008)$ y Telenomus sp. $(P=0,032)$ en el año 2008 (figura 5B, tabla 4).

\section{Discusión}

Riqueza específica y abundancia de parasitoides

Los resultados mostraron un elevado número de taxones identificados de Hymenoptera Parasitica (anexo), que fue el grupo más heterogéneo de los estudiados en el mismo cultivo (Ribes et al., 2004; Piñol et al., 2008, 2012; Mestre et al., 2013). Como se observa en la tabla 1, Las especies de parasitoides fueron poco abundantes, hecho que probablemente se debe a su capacidad de especialización a diferentes hospedadores potenciales en este tipo de espacios abiertos, o bien a la acción de sus competidores, como son los depredadores e hiperparasitoides (Starý, 1970). De igual manera, los cambios que experimentó la plantación (como la eliminación de pesticidas y otros agroquímicos, la sustitución por fertilizantes naturales, el incremento de la humedad del suelo mediante nuevos sistemas de riego en beneficio del cultivo) potenciaron el desarrollo de una vegetación periférica anteriormente muy reducida (Hole et al., 2005). Por tanto, es lógico que, en la parcela de estudio, se hayan ido instalando numerosas especies vegetales $\mathrm{y}$, con ellas, sus formas fitófagas asociadas, sus depredadores y sus parásitos. Es probable que este fenómeno esté relacionado directamente con la mayoría de las especies capturadas (anexo), dado que muchas de ellas no guardan una vinculación directa con las que viven a expensas de los cítricos, pero, sin duda, usan estos árboles como reposaderos alternativos previos a la búsqueda de su hospedador.

El mayor número de especies de parasitoides encontrados lo son, según la bibliografía, de Diptera (un 26\% de todas las especies), seguido de Lepidoptera (un $21 \%$ ) y Hemiptera. En este último grupo, cabe diferenciar las superfamilias Coccoidea (un 14\%) y Aphidoidea (un 13\%).

Los dípteros más comunes como controladores biológicos son los sírfidos y los cecidómidos como depredadores de diversas plagas, principalmente pulgones 

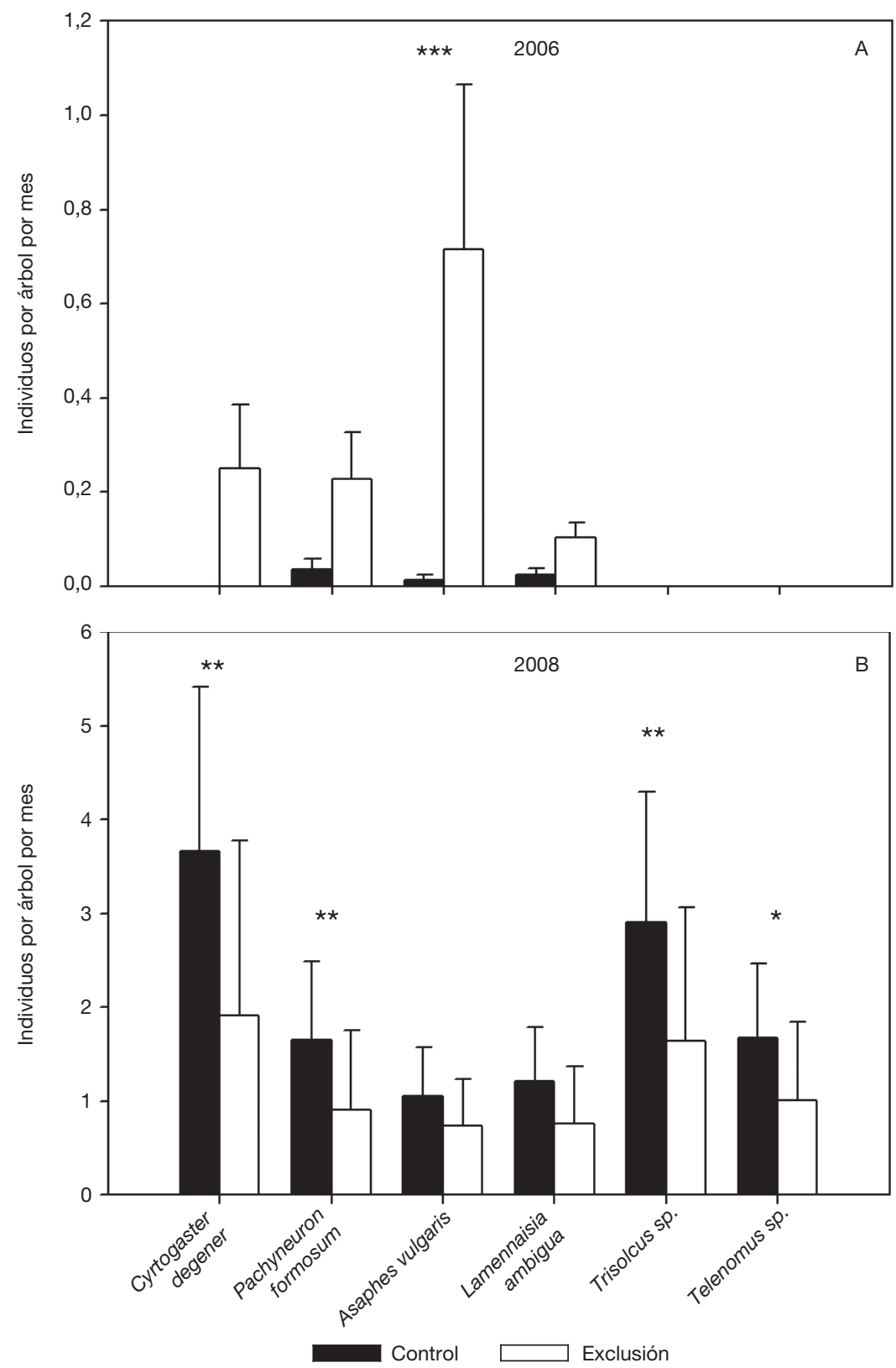

Figura 5. Abundancia de las especies más importantes entre tratamientos, dada como la media del número de individuos en cada árbol en los años 2006 (A) y 2008 (B), respectivamente. Las barras indican el error estándar (EE). Los asteriscos indican la significación estadística de la media anual entre ambos tratamientos $(* P<0,05 ; * * P<0,01 ; * * * P<0,001)$. 
(Gilbert, 1993; Sastre-Vega, 2007). En los cítricos, la mosca mediterránea de la fruta, Ceratitis capitata Wiedemann, 1824, es frecuente, al igual que en muchas plantas silvestres, por lo que los parasitoides pueden controlar mejor sus poblaciones por su alta capacidad de búsqueda (Adán et al., 2008). Nuestros resultados (anexo) muestran también como los parasitoides tienen preferencia hacia los dípteros Agromyzidae, una de las familias más comunes de minadores de hojas, controlados principalmente por bracónidos y eulófidos (Malais y Ravensberg, 2006), como es el caso del himenóptero Cyrtogaster degener, uno de los parasitoides más abundantes en nuestros muestreos.

Entre los lepidópteros, el minador de las hojas de los cítricos Phyllocnistis citrella Staintoni, 1856 es muy frecuente, aunque parece carecer de importancia para la producción de frutos. Los parasitoides de la familia Eulophidae engloban el mayor número de enemigos de esta plaga (Vercher et al., 1995; Urbaneja et al., 1998). Las otras especies de lepidópteros hospedadores de parasitoides parecen estar relacionados con otros tipos de plantas herbáceas asociadas al cultivo de cítricos, como es el caso de los Noctuidae.

En este trabajo, las especies de parasitoides con mayor número de individuos atacan a los áfidos, tanto de los cítricos como de otras plantas. Pertenecen principalmente a las familias Pteromalidae, Figitidae y Braconidae, hecho que es muy habitual en este tipo de agroecosistemas (Llorens, 1990; Urbaneja et al., 2008). Los pteromálidos también suelen atacar a los Coccidae (Hemiptera) (Jacas et al., 2008). Nuestros resultados presentan el parasitoide Pachyneurom formosum como uno de los más abundantes (figura 2), reportado como hiperparasitoide de parasitoides primarios en áfidos de cítricos (Michelena y Sanchis, 1997; Kavallieratos et al., 2002) y de pupas de sírfidos (Krawczyk et al., 2011), al igual que el género Asaphes, parasitoides muy comunes de áfidos en gramíneas y compuestas (Müller et al., 1997; Lumbierres et al., 2007). Seguidamente, se encuentra Lamennaisia ambigua (figura 2), perteneciene a la familia Encyrtidae, que cuenta con aproximadamente 300 especies en España (Noyes, 2003). Esta especie parasita diversas plagas, como Bruchus brachialis Fahraeus, 1837 (Coleoptera: Bruchidae) y Icerya purchasi Maskell, 1878 (Hemiptera: Margarodidae), muy común también en los cítricos (Urbaneja et al., 2008).

\section{Variación de los parasitoides en el tiempo}

Los resultados obtenidos muestran que hubo cambios en la abundancia y diversidad de las poblaciones de los Hymenoptera Parasitica en los árboles control. A partir del año 2006 (figura 3), el número de individuos se incrementa, y así anualmente hasta 2008. Podemos atribuir estos cambios a que, en 2004, se dejaron de usar productos agroquímicos, con lo que el agroecosistema necesitó un tiempo de adaptación a las nuevas circunstancias y, de un modo principal, la diversidad de especies asociadas al cultivo (Hole et al., 2005). También en el año 2006 se mejoró el sistema de riego para acelerar la descomposición del abono orgánico, lo que supuso un aumento de la vegetación asociada. Altieri (1999) señala un incremento en las poblaciones de insectos en los agroecosistemas cuando el porcentaje 
de vegetación que los rodea es alto y diverso. Lógicamente, se incrementa a su vez la abundancia de las formas fitófagas y la eficiencia de sus depredadores y parasitoides. Las variaciones temporales detectadas en nuestro estudio obedecen probablemente a esta doble circunstancia. Algunos estudios revelan un comportamiento similar en otros grupos de artrópodos, principalmente insectos depredadores y otros enemigos naturales (Bengtsson et al., 2005). De todas formas, las posibles causas de la variación interanual de la abundancia de microhimenópteros deben tomarse como simples hipótesis, ya que el estudio no se ha replicado en otras fincas cercanas.

\section{Efecto de la exclusión de hormigas}

El número de parasitoides en árboles sin hormigas fue mayor que en árboles control, lo que se explica por el rol negativo que ejercen estas especies sobre los enemigos naturales de los pulgones (Völk1, 1997; Kaneko, 2003a, 2003b). Durante la primera etapa de muestreo, la abundancia de los parasitoides fue muy baja, pero se fue incrementando en los años siguientes, quizás como consecuencia de la transición de cultivo convencional a cultivo ecológico. De forma similar, en la misma parcela, se había observado un efecto negativo parecido en la abundancia de otros artrópodos en presencia de hormigas durante el segundo periodo de estudio (2006-2009) (Piñol et al., 2012). En nuestro trabajo, de los cinco años estudiados, solo los años 2006 y 2008 presentaron diferencias significativas entre tratamientos con respecto al número de parasitoides (tabla 3 ), siendo más abundantes en árboles sin hormigas en el 2006 y menos abundantes en el 2008 (figura 4).

Estos resultados se deben a la presencia desigual de diversas especies de parasitoides. Sucede así en el año 2006, donde la especie que muestra diferencias en su abundancia entre tratamientos es Asaphes vulgaris (figura 5A, tabla 4), un pteromálido asociado con los cítricos (Kavallieratos et al., 2002) entre otros muchos cultivos, que vive como hiperparasitoide de diversos pulgones (Hemiptera: Aphidoidea), a través de varios Aphidiinae (Hymenoptera: Braconidae) (Garrido Torres y Nieves-Aldrey, 1999). También ha sido citada en una parcela de cítricos en Alicante como hiperparasitoide de los afidiinos presentes en el cultivo (Michelena y Sanchis, 1997), así como en cultivos de alfalfa en el Mediterráneo (Pons et al., 2011). Este resultado evidencia que la presencia de hormigas reduce el hiperparasitismo de áfidos parasitados y está en consonancia con los datos obtenidos por Kaneko (2002) en un cultivo de cítricos ecológico en Japón.

En el año 2008, predominaron dos especies de pteromálidos con diferencias entre tratamientos, Cyrtogaster degener y Pachyneuron formosum (figura 5B, tabla 4), que fueron un poco más abundantes en árboles control. Con respecto a la primera especie, es frecuente que parasite especies de Diptera (Jacas et al., 2008). Algo similar sucede también con los Scelionidae, con representación de los taxones Trissolcus sp. y Telenomus sp. (figura 5B, tabla 4), que son endoparásitos de huevos de diversos artrópodos (Austin y Field, 1997) y agentes potenciales de control biológico (Austin et al., 2005). El género Telenomus Haliday, 1833 ha sido 
asociado principalmente con los grupos Heteroptera y Lepidoptera (Masner, 1995), que atacan las puestas de diversas especies. Ambos son numerosos durante ese periodo en los árboles sin hormigas. Por tanto, la abundancia de parasitoides en este grupo de árboles control pudo ser la consecuencia del incremento de puestas de dichos grupos en la plantación, ya que la mayoría de plagas que atacan a estas especies no son mutualistas con las hormigas como lo son los pulgones.

En nuestro caso, los experimentos de exclusión revelan que la presencia de hormigas reduce circunstancialmente la abundancia de los parasitoides, pero no afecta de manera significativa a su acción sobre las poblaciones de plagas.

\section{Agradecimientos}

A la Sra. Núria Cañellas, por acceder generosamente a la manipulación de los árboles en los campos de mandarinos; a José M. Michelena, Juli Pujade, Daniel Ventura y Antoni Ribes, por su inestimable ayuda en las tareas de identificación de los Hymenoptera Parasitica, y al Dr. Ramón Vilanova, por permitirme acceder a una beca del programa E2NHANCE para mis estudios de doctorado. Este trabajo se ha realizado en el marco del proyecto MCYT-FEDER (CGL2010-18182).

A los dos revisores anónimos por sus acertadas correcciones y comentarios.

\section{Referencias bibliográficas}

Adán, A.; Medina, P.; Estal, P. del; Viñuela, E.; Budia, F. 2008. Control biológico de moscas de la fruta. Control Biológico de Plagas Agrícolas. In: Jacas, J.A.; Urbaneja, A. (Eds.). PHYTOMA. Capítulo 20: 324-333.

Albajes, R.; Alomar, O. 2008. Regulación de poblaciones por enemigos naturales y su aplicación en el control biológico de plagas. Control Biológico de Plagas Agrícolas. In: Jacas, J. A.; Urbaneja, A. (Eds.). PHYTOMA. Capítulo 3: 25-37.

Altieri, M.A. 1999. The ecological role of biodiversity in agroecosystems. Agric. Ecosyst. Environ. 74: 19-31.

Anento, J.L.; Selfa, J. 1997. Himenopteros Parasitica y control de plagas. Bol. Soc. Entomol. Aragonesa 20: 151-160.

Askew, R.R. 1971. Parasitic insects. Heinemann Educational Books Ltd. London. UK. $316 \mathrm{pp}$.

Askew, R.R. 1975. Some Chalcidoidea from Majorca, with descriptions of two new species (Hymenoptera). Eos: Revista Española de Entomología 49: 16-18.

Austin, A.D.; Field, S.A. 1997. The ovipositor system of scelionid and platygastrid wasps (Hymenoptera: Platygastroidea): Comparative morphology and phylogenetic implications. Invertebr. Taxon 11: 1-87.

Austin, A.D.; Johnson, N.F.; Dowton. M. 2005. Systematics, evolution, and biology of Scelionid and Platygastrid wasps. Ann. Rev. Entomol. 50: 553-82.

Avilla, J. 2005. Agentes entomófagos de control biológico de plagas: El control biológico de plagas y enfermedades. In: Jacas, J.; Caballero, P.P.; Avilla, J. (Eds.). Publicaciones de la Universitat Jaume I / Universidad Pública de Navarra. Castelló de la Plana. 51-65 pp.

Barbagallo, S.; Cravedi, P.; Pascualini, E.; Patti, I. 1998. Pulgones de los principales cultivos frutales. Bayer y Ediciones Mundi-Prensa. Madrid, $225 \mathrm{pp}$. 
Belliure, B.; Pérez, P.; Marcos, M.A.; Michelena, J.M.; Hermoso de Mendoza, A. 2008. Control Biológico de Pulgones. Control Biológico de Plagas Agrícolas. In: Jacas, J.A.; Urbaneja, A. (Eds.). PHYTOMA. Capítulo 14: 209-238.

Bengtsson, J.; Ahnström. J.; Weibull, A.-C. 2005. The effects of organic agriculture on biodiversity and abundance: A meta-analysis. J. Appl. Ecol. 42: 261-269.

Boucek, Z.; Rasplus, J.Y. 1991. Illustrated key to West-Paleartic Genera of Pteromalidae. INRA Editions. Paris. 140 pp.

Ceballos, G. 1964. Segundo suplemento al catálogo de los himenópteros de España. Eos: Revista Española de Entomología, 40: 43-97.

Clarke, K.R.; Gorley, R.N. 2006. Primer v6: User Manual/Tutorial. PRIMER-E. Plymouth. $190 \mathrm{pp}$.

Ebeling, W. 1959. Subtropical Fruit Pests. University of California. Division of Agricultural Sciences. Riverside, California, $436 \mathrm{pp}$.

Fergusson, N.D.M. 1986. Charipidae, Ibaliidae and Figitidae (Hymenoptera: Cynipoidea). N.D.M. Fergusson: Handbooks for the Identification of British Insects. Royal Entomological Society. London. Vol. 8. Part 1c. 55 pp.

Fernández, F.; Sharkey, M.J. 2006. Introducción a los Hymenoptera de la Región Neotropical. Serie Entomología Colombiana. Sociedad Colombiana de Entomología. Bogotá D.C. Colombia, 896 pp.

Ferrer-Suay, M.; Selfa, J.; Pujade-Villar, J. 2012. Taxonomic revision of the Alloxysta brevis group (Hymenoptera, Cynipoidea, Figitidae, Charipinae). Boletín de la Sociedad Entomológica Aragonesa, 51: 237-249.

Fontal, F.; Nieves-Aldrey, J.L. 2004. Estudio comparado de diversidad de Eucoilinos paleárticos (El Ventorillo, España) y Neotropicales (Coiba, Panama) (Hymenoptera, Cynipoidea, Figitidae, Eucoilinae). Boletin SEA, 35: 51-101.

Forshage, M.; Nordlander, G. 2008. Identification key to European genera of Eucoilinae (Hymenoptera, Cynipoidea, Figitidae). Insect Systematics and Evolution, 39: 341-359.

Garcia-Marí, F.; Ohlenschläeger, F.; Soto, A.; Olmeda, T. 1996. Introducción en los cítricos españoles de un insecto beneficioso, Eretmocerus debachi, parasitoide de la mosca blanca japonesa Parabemisia myricae. Levante Agrícola 334: 34-37.

Garcia-Marí, F.; Vercher, R.; Costa-Comelles, J.; Marzal, C.; Villalba, M. 2004. Establishment of Citrostichus phyllocnistoides (Hymenoptera: Eulophidae) as a biological control agent for the citrus leafminer Phyllocnistis citrella (Lepidoptera: Gracillariidae), Spain. Biol. Control 29: 215-226.

Garrido-Torres, A.M.; Nieves-Aldrey, J.L. 1999. Pteromálidos de la comunidad de Madrid: faunística y catálogo (Hymenoptera, Chalcidoidea, Pteromalidae). Graellsia 55: 9-147.

Garrido-Torres, A.; Ventura, J.J. 1993. Plagas de los cítricos. In: Bases para el manejo integrado. Ministerio de Agricultura, Pesca y Alimentación (Ed.). Madrid. 183 pp.

Gaston, K.J. 1993. Spatial patterns in the description and richness of the Hymenoptera. In: Hymenoptera and Biodiversity. La Salle, J.; Gauld, I. (Eds.). C.A.B. International. Wallingford, UK: 277-293 pp.

Gauld, I.D.; Bolton, B. 1988. The Hymenoptera. British Museum \& Oxford University. United Kingdom. 352 pp.

Gilbert, F.S. 1993. Hoverflies: Naturalist's Handbooks. The Richmond Publishing Co., Slough. 67 pp.

Godfray, H.C.J. 1994. Parasitoids. Behavioral and Evolutionary Ecology. Princeton University Press. Princeton. UK. 475 pp.

Gordh, G.; Legner, E.F.; Caltaggirone, L.E. 1999. Biology of parasitic Hymenoptera. In: 
Bellows, T.S.; Fisher, T.W. (Eds.). Handbook of biological control: 355-381. Academic Press.

Goulet, H.; Huber, J.T. 1993. Hymenoptera of the World: An identification guide to families. Agriculture Canada. 688 pp.

Graham, M.W.R. de V., 1969. The Pteromalidae of northwestern Europe (Hymenoptera: Chalcidoidea). Bull. Br. Mus. Nat. Hist. (Ent.), Suppl. 16: 1-980.

Hagler, J.R. 2000. Biological control of insects. In: Rechcigl, J.E.; Rechcigl, N.A. (Eds.). Insect pest management. Techniques for environmental protection. Lewis Publishers. USA. pp. 207-241.

Hajek, A.E. 2004. Natural enemies: An introduction to biological control. Cambridge. University Press, Cambridge, England. 394 pp.

Hermoso de Mendoza, A.; Esteve, R.; Llorens, J.M.; Michelena, J.M. 2012. Evolución global y por colonias de pulgones (Hemiptera, Aphididae) y sus enemigos naturales en clementinos y limoneros valencianos. Bol. Sanid. Veg., Plagas. 38: 61-71.

Hermoso de Mendoza, A.; Pérez, E.; Real, V. 1997. Composición y evolución de la fauna afídica (Homoptera, Aphidinea) de los cítricos valencianos. Bol. sanid. veg., Plagas. 23: 363-375.

Hole, D.G.; Perkins, A.J.; Wilson, J.D.; Alexander, I.H.; Grice, F.; Evans, A.D. 2005. Does organic farming benefit biodiversity? Biol. Conserv. 122: 113-130.

Jacas, J.A.; Urbaneja, A.; Garcia-Marí, F. 2008. Artrópodos depredadores. Control Biológico de Plagas Agrícolas. Jacas, J.A; Urbaneja, A. (Eds.). PHYTOMA. Capítulo 4: 39-56.

Kaneko, S. 2002. Aphid-attending Ants Increase the Number of Emerging Adults of the Aphid's Primary Parasitoid and Hyperparasitoids by Repelling Intraguild Predators. Entomol. Sci. 5: 131-146.

Kaneko, S. 2003a. Different impacts of two species of aphid-attending ants with different aggressiveness on the number of emerging adults of the aphid's primary parasitoid and hyperparasitoids. Ecol. Res. 18: 199-212.

Kaneko, S. 2003b. Impacts of two ants, Lasius niger and Pristomyrmex pungens (Hymenoptera: Formicidae), attending the brown citrus aphid, Toxoptera citricidus (Homoptera: Aphididae), on the parasitism of the aphid by the primary parasitoid, Lysiphlebus japonicus (Hymenoptera: Aphidiidae), and its larval survival. Appl. Entomol. Zool. 38: 347-357.

Kavallieratos, N.G.; Athanassiou, C.G.; Stathas, G.J.; Tomanovic, Z. 2002. Aphid Parasitoids (Hymenoptera: Braconidae: Aphidiinae) on Citrus: Seasonal Abundance, Association with the Species of Host Plant, and Sampling Indices. Phytoparasitica 30: 365-377.

Krawczyk, A.; Hurej, M.; Jackowski, J. 2011. Syrphids and their parasitoids from maize crop. J. Plant Prot. Res. 51: 93-97.

Lasalle, J.; Gauld, I.D. 1993. Hymenoptera: their diversity, and their impact on the diversity of other organisms. In: LaSalle J.; Gauld, I.D. (Eds.). Hymenoptera and Biodiversity. CAB International, Wallington, UK. 1-26 pp.

Llorens, C.J. 1990. Homóptera II: Pulgones de los cítricos y su control biológico. Pisa Ediciones. Alicante, $170 \mathrm{pp}$.

Lumbierres, B.; Starý, P.; Pons, X. 2007. Seasonal parasitism of cereal aphids in a Mediterranean arable crop system. J. Pest Sci. 80: 125-130.

Malais, M.; Ravensberg, W.J. 2006. Los minadores de hojas y sus enemigos naturales. In: Conocer y Reconocer: Las plagas de cultivos protegidos y sus enemigos naturales. Rotterdam. Kopper Biological Systems: 111-128. 
Martín-Piera, F.; Lobo, J.M. 2000. Diagnóstico sobre el conocimiento sistemático y biogeográfico de tres órdenes de insectos hiperdiversos en España: Coleoptera, Hymenoptera y Lepidoptera. Hacia un Proyecto CYTED para el Inventario y Estimación de la Diversidad Entomológica en Iberoamérica: PrIBES. 1: 287-308.

Masner, L. 1995. The proctotrupoid families. In: Hanson, P.; Gauld, I. (Eds.). Hymenoptera of Costa Rica. Oxford University Press. Oxford. Chapter 9: 209-246.

Mestre, L.; Piñol, J.; Barrientos, J.A.; Espadaler, X. 2013. Ant exclusion in citrus over an 8-year period reveals a pervasive yet changing effect of ants on a Mediterranean spider assemblage. Oecologia 173: 239-48.

Michelena, J.M.; González, P.; Soler, E. 2004. Parasitoides afidiinos (Hymenoptera, Braconidae, Aphidiinae) de pulgones de cultivos agrícolas en la Comunidad Valenciana. Bol. Sanid. Veg., Plagas 30: 317-326.

Michelena, J.M.; Sanchis, A. 1997. Evolución del parasitismo y fauna útil sobre pulgones en una parcela de cítricos. Bol. Sanid. Veg., Plagas 23: 241-255.

Michelena, J.M.; Sanchos, A.; González, P. 1994. Afidiinos sobre pulgones de frutales en la Comunidad Valenciana. Bol. Sanid. Veg., Plagas 20: 465-470.

Müller, C.B.; Godfray, H.C.J. 1999. Predators and mutualists influence the exclusion of aphis species from natural communities. Oecologia, 119: 120-125.

Müller, C.B.; Völkl, W.; Godfray, C.J. 1997. Are behavioural changes in parasitized a protection against hyperparasitism? Eur. J. Entomol. 94: 221-234.

Nieves-Aldrey, J.L. 2001. Hymenoptera, Cynipidae. In: Ramos, M.A. (Eds.). Fauna Ibérica, 16. Museo Nacional de Ciencias Naturales. CSIC. Madrid. 636 pp.

Nieves-Aldrey, J.L. 2008. Redescubrimiento de Aulacidea kiefferi Cotte, 1915 (Hymenoptera, Cynipidae), con redescripción del adulto y del último estado larval. Graellsia, 64(2): 295-305.

Nieves-Aldrey, J.L.; Fontal-Cazalla, F.; Garrido-Torres, A.M.; Rey del Castillo, C. 2003. Inventario de Hymenoptera (Hexapoda) en El Ventorillo: Un rico enclave de biodiversidad en la Sierra de Guadarrama (España Central). Graellsia, 59(2-3): 25-43.

Nieves-Aldrey, J.L.; Sánchez, I.; Massa, B.; Gómez, J.F. 2008. Cynipid wasps inducing galls on plants of the genus Picris (Asteraceae) in Europe, with a description of a new species of Phanacis Foerster (Hymenoptera: Cynipidae) from the Iberian Peninsula. Annales de la Societé entomologique de France, 44(3): 257-269.

Novak, H. 1994. The influence of ant attendance on larval parasitism in hawthorn psyllids (Homoptera: Psyllidae). Oecologia, 99: 72-78.

Noyes, J.S. 2003. Universal Chalcidoidea Database. World Wide Web electronic publication. www.nhm.ac.uk/entomology/chalcidoids/index.html

Pina, T. 2008. Insectos parasitoides. Control Biológico de Plagas Agrícolas. In: Jacas, J.A.; Urbaneja, A. (Eds.). PHYTOMA. Capítulo 5: 57-85.

Piñol, J.; Espadaler, X.; Cañellas, N.; Barrientos, J.A.; Muñoz, J.; Pérez, N.; Ribes, E.; Ribes, J. 2008. Artrópodos de un campo ecológico de mandarinos. Sessió Conjunta d'Entomologia, ICHN-SCL, 13-14: 57-72.

Piñol, J.; Espadaler, X.; Cañella, N. 2012. Eight years of ant-exclusion from citrus canopies: Effects on the arthropod assemblage and on fruit yield. Agric. Forest Entomol. 14: 49-57.

Pons, X.; Lumbierres, B.; Ribes, A.; Stary, P. 2011. Parasitoid complex of alfalfa aphids in an IPM intensive crop system in northern Catalonia. J. Pest Sci. 84: 437-445.

Ribes, J.; Piñol, J.; Espadaler, X.; Cañellas, N. 2004. Heteropteros de un cultivo ecológico de cítricos de Tarragona (Cataluña, NE España) (Hemiptera: Heteroptera). Orsis, 19: 21-35. 
Ros-Farré, P.; Pujade-Villar, J. 1997. Figítids sensu stricto detectats a la Península Ibèrica (Hymenoptera, Figitidae: Figitinae, Anacharitinae, Aspicerinae). Ses. Entom. ICHNSCL, 10: 123-134.

Ros-Farré, P.; Pujade-Villar, J. 2009. Revision of the genus Callaspidia Dahlbom, 1842 (Hym.: Figitidae: Aspicerinae). Zootaxa, 2105: 1-31.

Samways, M.J.; Tate, B.A. 1985. A highly efficacious and inexpensive trunk barrier to prevent ants from entering citrus trees. Citrus Subtropicale Fruit Journal, 618: 12-14.

Sastre Vega, M. 2007. Influencia del manejo de la cubierta vegetal en la población de áfidos y su fauna auxiliar asociada en cítricos. Trabajo de fin de carrera. Ingeniería Agrónoma. Escuela Politécnica Superior de Orihuela. Universidad Miguel Hernández.

Sharkey, M. 2007. Phylogeny and classification of Hymenoptera. Zootaxa 1668: 521-548.

Soler, J.M.; Garcia-Marí, F.; Alonso, D. 2002. Evolución estacional de la entomofauna auxiliar en cítricos. Bol. Sanid. Veg., Plagas 28: 133-149.

Starý, P. 1970. Biology of aphid parasites (Hymenoptera: Aphidiidae) with respect to integrated control. Series Entomological 6. Dr. W. Junk. The Hague. 643 pp.

Suay-Cano, V.A.; Luna-Martínez, F.; Michelena-Saval, J.M. 1998. Parasitoides no afidiinos de pulgones (Chalcidoidea: Aphelinidae) e hiperparasitoides de las superfamilias Chalcidoidea, Ceraphronoidea y Cynipoidea (Hymenoptera: Apocrita: Parastitica) en la provincia de Valencia. Boletín de la Asociación Española de Entomología, 22(1-2): 99-113.

Sullivan, D.J.; Völkl, W. 1999. Hyperparasitismo: Multitrophic Ecology and Behavior. Annu. Rev. Entomol. 44: 291-315.

Urbaneja, A.; Jacas, J.A.; Garcia-Marí, F. 2008. Control biológico en cítricos. Control Biológico de Plagas Agrícolas. In: Jacas, J.A.; Urbaneja, A. (Eds.). PHYTOMA. Capítulo 21: 335-348.

Urbaneja, A.; Jacas., J.; Verdú, M.J.; Garrido, A. 1998. Dinámica e impacto de los parasitoides autóctonos de Phyllocnistis citrella Stainton, en la Comunidad Valenciana. Investigación Agraria. Producción y protección vegetales 13: 409-423.

Vercher, R.; Verdú, M.J.; Costa Comelles, J.; García Marí, F. 1995. Parasitoides autóctonos del minador de hojas de cítricos Phyllocnistis citrella en las comarcas centrales valencianas. Levante Agrícola 14: 306-312.

Verdú, M.J. 1985. Establecimiento de Prospaltella elongate, parasite de serpent fina. Levante Agrícola 259-260: 68-70.

Viggiani, G. 2000. The role of parasitic Hymenoptera in integrated pest management in fruit orchards. Crop Prot. 19: 665-668.

Völkl, W. 1997. Interactions between ants and aphid parasitoids: Patterns and consequences for resource utilization. Ecol. Stud. 130: 225-240.

Way, M.J. 1963. Mutualism between ants and honeydew producing homoptera. Annu. Rev. Entomol. 8: 307-344.

Zuparko, R.L. 2008. Parasitic Hymenoptera (Parasitica). In: Capinera, J.L. (Eds.). Encyclopedia of Entomology. Springer Science. Germany. 2730-2736 pp. 


\section{Anexo}

Relación de todas las especies de parasitoides capturadas, con indicación de sus hospedadores respectivos (se trata, lógica e inevitablemente, de una indicación orientativa sujeta a complementos y correcciones). Se detalla el número de individuos capturados por año de cada especie y las familias correspondientes.

\begin{tabular}{lll}
\hline & Número de individuos por año & \\
\cline { 2 - 3 } Especie & 20042005200620072008 Total & Hospedador \\
\hline
\end{tabular}

\section{Ceraphronidae}

\begin{tabular}{|c|c|c|c|c|c|c|c|}
\hline Aphanogmus sp.1 & 0 & 2 & 0 & 0 & 3 & 5 & Género con parasitoides de \\
\hline Aphanogmus sp.2 & 0 & 0 & 0 & 1 & 0 & 1 & idómidos, de neurópteros e \\
\hline Aphanogmus sp.3 & 0 & 0 & 0 & 1 & 1 & 2 & $\begin{array}{l}\text { hiperparasitoides en diversos } \\
\text { órdenes. }\end{array}$ \\
\hline $\begin{array}{l}\text { Aphanogmus } \\
\text { steinitzi Priesner, } \\
1936\end{array}$ & 0 & 1 & 2 & 13 & 17 & 33 & $\begin{array}{l}\text { Parasitoides de neurópteros, } \\
\text { familia Coniopterygidae. }\end{array}$ \\
\hline
\end{tabular}

\begin{tabular}{|c|c|c|c|c|c|c|c|}
\hline Ceraphron sp. & 0 & 0 & 0 & 1 & 3 & 4 & $\begin{array}{l}\text { Parasitoides en agallas de } \\
\text { cecidómidos; también sobre } \\
\text { áfidos y nidos de hormigas. }\end{array}$ \\
\hline Synarsis sp. & 1 & 0 & 1 & 0 & 0 & 2 & $\begin{array}{l}\text { Parasitoides sobre dípteros, } \\
\text { tisanópteros, lepidópteros y } \\
\text { neurópteros. Algunas especies } \\
\text { son hiperparasitoides de áfidos, } \\
\text { vía Braconidae. }\end{array}$ \\
\hline
\end{tabular}

\section{Megaspilidae}

\begin{tabular}{|c|c|c|c|c|c|c|c|}
\hline Conostigmus sp.1 & 0 & 0 & 1 & 0 & 1 & 2 & Género con parasitoides \\
\hline Conostigmus sp.2 & 0 & 0 & 1 & 2 & 0 & 3 & $\begin{array}{l}\text { (frecuentemente sobre cóccidos } \\
\text { de Heliococcus bohemicus Sulc, } \\
1912 \text { y pupas de Syrphidae). }\end{array}$ \\
\hline
\end{tabular}

\begin{tabular}{llllllll}
\hline Dendrocerus sp.1 & 1 & 0 & 0 & 1 & 2 & 4 & Parasitoides de neurópteros \\
\hline $\begin{array}{l}\text { Dendrocerus } \text { sp.2 } \\
\text { Dendrocerus } \text { sp. } 3\end{array}$ & 0 & 0 & 0 & 1 & 0 & 1 & $\begin{array}{l}\text { Coniopterygidae. } \\
\text { Hiperparasitoides de áfidos via } \\
\text { Braconidae Aphidiinae. }\end{array}$ \\
$\begin{array}{l}\text { Dendrocerus } \\
\text { aphidum } \text { Rondani, } \\
1877\end{array}$ & 0 & 3 & 0 & 0 & 0 & 3 & $\begin{array}{l}\text { Hiperparasitoides de áfidos, via } \\
\text { Braconidae Aphidiinae. }\end{array}$
\end{tabular}

\begin{tabular}{|c|c|c|c|c|c|c|c|}
\hline $\begin{array}{l}\text { Dendrocerus } \\
\text { ergensis } \\
\text { Ghesquiere, } 1960\end{array}$ & 0 & 0 & 0 & 1 & 1 & 2 & $\begin{array}{l}\text { Parasitoides de los coleópteros } \\
\text { Coccinellidae Scymnus y } \\
\text { Pharoscymnus; posiblemente } \\
\text { hiperparasitoides via Encyrtidae } \\
\text { de Homalotylus flaminius } \\
\text { Dalman. } 1820 .\end{array}$ \\
\hline
\end{tabular}




\begin{tabular}{|c|c|c|c|c|c|c|c|}
\hline \multirow[b]{2}{*}{ Especie } & \multicolumn{6}{|c|}{ Número de individuos por año } & \multirow[b]{2}{*}{ Hospedador } \\
\hline & 2004 & 2005 & 2006 & 2007 & 2008 & Total & \\
\hline $\begin{array}{l}\text { Dendrocerus } \\
\text { pupparum } \\
\text { Boheman, } 1832\end{array}$ & 0 & 0 & 1 & 2 & 2 & 5 & $\begin{array}{l}\text { Parasitoide de pupas de } \\
\text { Syprhidae. }\end{array}$ \\
\hline $\begin{array}{l}\text { Dendrocerus } \\
\text { serricornis } \\
\text { Boheman, } 1832\end{array}$ & 0 & 0 & 0 & 0 & 2 & 2 & $\begin{array}{l}\text { Parasitoides de dípteros del } \\
\text { género Leucopis y depredadores } \\
\text { de áfidos. }\end{array}$ \\
\hline Trichosteresis sp. & 1 & 1 & 0 & 1 & 2 & 5 & $\begin{array}{l}\text { Género con parasitoides de pupas } \\
\text { de Syrphidae. }\end{array}$ \\
\hline
\end{tabular}

\section{Aphelinidae}

\begin{tabular}{llllllll}
\hline Aphelinus sp. 1 & 0 & 0 & 0 & 0 & 1 & 1 & Parasitoides principalmente de
\end{tabular}

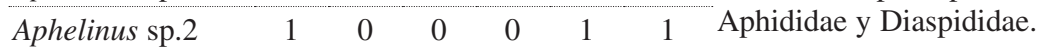

$\begin{array}{llllllll}\text { Aphelinus } & 0 & 0 & 1 & 0 & 0 & 1 & \text { Parasitoides de Aphididae. }\end{array}$

abdominalis

Dalman, 1820

\begin{tabular}{llllllll}
\hline Aphelinus chaonia & 0 & 0 & 0 & 0 & 1 & 1 & Parasitoides de diversos
\end{tabular}

Walker, 1839

Aphididae; entre otros, de Aphis spiraecola Patch, 1914, Aphis gossypii Glover, 1877 y Toxoptera aurantii Boyer de F., 1841.

\begin{tabular}{|c|c|c|c|c|c|c|c|}
\hline $\begin{array}{l}\text { Aphelinus } \\
\text { semiflavus } \\
\text { Howard, } 1908\end{array}$ & 0 & 0 & 0 & 0 & 0 & 1 & $\begin{array}{l}\text { Parasitoides de numerosos } \\
\text { áfidos, como Acyrtosiphon, } \\
\text { Aphis, Chaetosiphon, } \\
\text { Macrosiphum, Rhopalosiphum, } \\
\text { Therioaphis, Myzus persicae } \\
\text { (Sulzer, 1776), etc. }\end{array}$ \\
\hline
\end{tabular}

$\begin{array}{llllllll}\text { Aphelinus varipes } & 0 & 5 & 1 & 0 & 0 & 6 & \text { Parasitoides de áfidos que atacan }\end{array}$ Forster, 1841 gramíneas y otras plantas herbáceas; actúa sobre Toxoptera graminum Rond., Diuraphis noxia Kurdjumov, 1913, Rhopalosiphum maidis Fitch, 1856, Schizaphis graminum Rondani 1852, Sitobion avenae Fabricius, 1775, Aphis, Myzus, etc.

\begin{tabular}{|c|c|c|c|c|c|c|c|}
\hline $\begin{array}{l}\text { Cales noacki } \\
\text { Howard, } 1907\end{array}$ & 0 & 2 & 0 & 4 & 2 & 8 & $\begin{array}{l}\text { Parasitoides del hemíptero } \\
\text { Aleyrodidae, Aleurothrixus } \\
\text { floccosus Maskell, } 1896 . \\
\text { Ocasionalmente, sobre } \\
\text { Parabemisia myricae Kuwana, } \\
\text { 1927. Citado en Citrus sp., sobre } \\
\text { Aleurothrixus floccosus Maskell, } \\
\text { 1896. }\end{array}$ \\
\hline
\end{tabular}




\begin{tabular}{|c|c|c|c|c|c|c|c|}
\hline \multirow[b]{2}{*}{ Especie } & \multicolumn{6}{|c|}{ Número de individuos por año } & \multirow[b]{2}{*}{ Hospedador } \\
\hline & 2004 & 2005 & 2006 & 2007 & 2008 & Total & \\
\hline Coccophagus sp. & 0 & 0 & 1 & 0 & 0 & 1 & $\begin{array}{l}\text { Parasitoides de numerosos } \\
\text { hemípteros Coccidae; también } \\
\text { sobre Diaspididae, Margarodidae } \\
\text { y Pseudococcidae. Citado en } \\
\text { Citrus sp., sobre Coccus } \\
\text { hesperidum Linnaeus, } 1758, \\
\text { Ceroplastes sinensis Del } \\
\text { Guercio, } 1900 \text { y C. rusci } \\
\text { Linnaeus, } 1758 ; \text { también sobre } \\
\text { Saissetia oleae Olivier, } 1791 .\end{array}$ \\
\hline \multicolumn{8}{|l|}{ Chalcididae } \\
\hline Antrocephalus sp. & 0 & 0 & 1 & 1 & 0 & 2 & $\begin{array}{l}\text { Parasitoides de lepidópteros, } \\
\text { frecuentemente de Pyralidae; } \\
\text { Apomyelois ceratoniae Zeller, } \\
1839 \text { podría ser un posible } \\
\text { hospedador. }\end{array}$ \\
\hline Brachymeria sp.1 & 0 & 0 & 0 & 0 & 1 & 1 & \multirow{3}{*}{$\begin{array}{l}\text { Parasitoides e hiperparasitoides } \\
\text { de diversos lepidópteros. }\end{array}$} \\
\hline Brachymeria sp.2 & 1 & 0 & 0 & 0 & 1 & 2 & \\
\hline Brachymeria sp.3 & 0 & 0 & 0 & 1 & 3 & 4 & \\
\hline Haltichella sp. & 0 & 0 & 0 & 2 & 1 & 3 & $\begin{array}{l}\text { Parasitoides de lepidópteros, } \\
\text { Tortricidae y coleópteros } \\
\text { Anobiidae o Tenebrionidae. }\end{array}$ \\
\hline
\end{tabular}

\section{Encyrtidae}

\begin{tabular}{|c|c|c|c|c|c|c|c|}
\hline Acerophagus sp. & 0 & 0 & 0 & 1 & 0 & 1 & $\begin{array}{l}\text { Género con parasitoides de } \\
\text { hemípteros Pseudococcidae. }\end{array}$ \\
\hline Ageniaspis sp. & 0 & 1 & 1 & 0 & 0 & 2 & $\begin{array}{l}\text { Parasitoides de Prays oleae } \\
\text { Bernard, 1788; también sobre } \\
\text { Prays citri Millière, } 1873 \text { en } \\
\text { Citrus x limón Burm.f, } 1768 .\end{array}$ \\
\hline Aschitus sp. & 0 & 0 & 1 & 1 & 1 & 3 & $\begin{array}{l}\text { Parasitoides del hemítero } \\
\text { Eriococcidae Micrococcus similis } \\
\text { Leonardi, 1907, en gramíneas. }\end{array}$ \\
\hline Blastothrix sp. & 0 & 1 & 0 & 0 & 0 & 1 & $\begin{array}{l}\text { Parasitoides de hemípteros } \\
\text { Coccidae; también de } \\
\text { Diaspididae y Pseudococcidae. }\end{array}$ \\
\hline Bothriothorax sp. & 0 & 0 & 0 & 0 & 1 & 1 & $\begin{array}{l}\text { Sobre dípteros Syrphidae: } \\
\text { Syrphus, Episyrphus, Scaeva, etc. }\end{array}$ \\
\hline Cheiloneurus sp. & 0 & 0 & 0 & 1 & 5 & 6 & $\begin{array}{l}\text { Parasitoides de dípteros } \\
\text { Syrphidae e hiperparasitoide (via } \\
\text { Dryinidae: Neodryinus } \\
\text { typhlocybae Ashmead, 1893) en } \\
\text { adultos del Flatidae Metcalfa } \\
\text { pruinosa Say, } 1830 .\end{array}$ \\
\hline
\end{tabular}




\begin{tabular}{|c|c|c|c|c|c|c|c|}
\hline \multirow[b]{2}{*}{ Especie } & \multicolumn{6}{|c|}{ Número de individuos por año } & \multirow[b]{2}{*}{ Hospedador } \\
\hline & 2004 & 2005 & 2006 & 2007 & 2008 & Total & \\
\hline Copidosoma sp.1 & 2 & 0 & 0 & 0 & 0 & 2 & \multirow[b]{3}{*}{$\begin{array}{l}\text { Parasitoides de lepidópteros } \\
\text { Noctuidae Plusiinae: Agrapha } \\
\text { agnata Staudinger, 1892, A. } \\
\text { tarassota Hampson 1913, } \\
\text { Argyrogramma signatum } \\
\text { Fabricius, 1775, Chrysodeixis } \\
\text { acuta Walker, 1858, C. } \\
\text { argentifera Guenée, 1852, C. } \\
\text { chalcites Esper, 1789, Mamestra } \\
\text { brassicae L, 1758, Nebrarctia } \\
\text { obliqua, Plusia sp., Pseudoplusia } \\
\text { includens Walk., Rachiplusia nu } \\
\text { Guenée, 1852, Thysanoplusia } \\
\text { orichalcea Fabricius, 1775, etc. }\end{array}$} \\
\hline Copidosoma sp.2 & 0 & 1 & 0 & 0 & 0 & 1 & \\
\hline Copidosoma sp.3 & 0 & 2 & 1 & 0 & 0 & 3 & \\
\hline $\begin{array}{l}\text { Copidosomopsis } \\
\text { sp. }\end{array}$ & 1 & 0 & 0 & 0 & 0 & 1 & $\begin{array}{l}\text { Género con parasitoides } \\
\text { poliembriónicos de lepidópteros } \\
\text { Pyralidae y Tortricidae. }\end{array}$ \\
\hline Cowperia sp. & 0 & 0 & 0 & 0 & 1 & 1 & $\begin{array}{l}\text { Parasitoides en pupas de } \\
\text { coleópteros: de los Coccinellidae } \\
\text { Cryptolaemus montrouzieri } \\
\text { Mulsant, } 1850 \text { y de Scymnus } \\
\text { apetzi Mulsant, } 1846 .\end{array}$ \\
\hline Encyrtus sp. & 0 & 0 & 0 & 1 & 0 & 1 & $\begin{array}{l}\text { Parasitoides de numerosos } \\
\text { hemípteros Coccidae. }\end{array}$ \\
\hline Ericydnus sp.1 & 0 & 0 & 0 & 1 & 0 & 1 & Parasitoides de hemípteros \\
\hline Ericydnus sp.2 & 0 & 0 & 0 & 3 & 6 & 9 & Coccidae. \\
\hline Eupoecilopoda sp. & 0 & 0 & 0 & 1 & 0 & 1 & $\begin{array}{l}\text { Parasitoides de huevos de } \\
\text { Chrysopa } \text { sp. }\end{array}$ \\
\hline $\begin{array}{l}\text { Homalotyloidea } \\
\text { sp. }\end{array}$ & 0 & 2 & 0 & 0 & 1 & 3 & $\begin{array}{l}\text { Parasitoides de los coleópteros } \\
\text { Coccinellidae, Rhizobius litura } \\
\text { Fabricius, 1787, e } \\
\text { hiperparasitoides en } \\
\text { Coccinellidae via Homalotylus } \\
\text { flaminius Dalman, } 1820 .\end{array}$ \\
\hline Homalotylus sp.1 & 2 & 0 & 0 & 0 & 0 & 2 & $\begin{array}{l}\text { Parasitoides de los coleópteros } \\
\text { Coccinellidae Scymnus } \\
\text { subvillosus Goeze. y Platynaspis } \\
\text { luteorubra Goeze, } 1777 .\end{array}$ \\
\hline Homalotylus sp.2 & 0 & 2 & 0 & 0 & 0 & 2 & $\begin{array}{l}\text { Parasitoides de los coleópteros } \\
\text { Coccinellidae Exochomus, } \\
\text { Chilocorus e Hyperaspis. }\end{array}$ \\
\hline Isodromus sp. & 2 & 2 & 0 & 1 & 1 & 6 & $\begin{array}{l}\text { Parasitoides de huevos de } \\
\text { neurópteros, generalmente de } \\
\text { Chrysopa } \mathrm{sp} \text {. }\end{array}$ \\
\hline
\end{tabular}




\begin{tabular}{|c|c|c|c|c|c|c|c|}
\hline \multirow[b]{2}{*}{ Especie } & \multicolumn{6}{|c|}{ Número de individuos por año } & \multirow[b]{2}{*}{ Hospedador } \\
\hline & 2004 & 2005 & 2006 & 2007 & 2008 & Total & \\
\hline $\begin{array}{l}\text { Lamennaisia } \\
\text { ambigua Nees, } \\
1976\end{array}$ & 28 & 26 & 22 & 127 & 64 & 267 & $\begin{array}{l}\text { Parasitoides del hemíptero } \\
\text { Margarodidae Icerya purchasi } \\
\text { Maskell, 1878, y de coleópteros } \\
\text { Lathrididae y Bruchidae. }\end{array}$ \\
\hline Lamennaisia sp. & 0 & 0 & 0 & 0 & 1 & 1 & $\begin{array}{l}\text { Parasitoides sobre el coleóptero } \\
\text { Bruchidae Bruchus brachialis } \\
\text { Fahraeus, } 1839 \text { y el hemíptero } \\
\text { Margarodidae Icerya purchasi } \\
\text { Maskell, 1878; también se ha } \\
\text { citado en el coléptero Latridiidae } \\
\text { Melanophthalma sp. }\end{array}$ \\
\hline
\end{tabular}

\begin{tabular}{lcccccc}
\hline Metaphycus sp.1 & 0 & 10 & 0 & 0 & 0 & 10 \\
\hline Metaphycus sp.2 & 0 & 0 & 0 & 0 & 4 & 4 \\
\hline Metaphycus sp. 3 & 8 & 0 & 2 & 0 & 2 & 12 \\
\hline Metaphycus sp.4 & 2 & 10 & 12 & 3 & 1 & 28 \\
\hline Metaphycus sp.5 & 0 & 0 & 2 & 0 & 0 & 2 \\
\hline Metaphycus sp.6 & 8 & 6 & 2 & 1 & 5 & 22 \\
\hline Microterys sp. 1 & 0 & 0 & 0 & 0 & 1 & 1 \\
\hline Microterys $\mathrm{sp} .2$ & 6 & 2 & 0 & 0 & 2 & 10
\end{tabular}

Parasitoides de hemípteros Coccidae, en Citrus sp., sobre Saissetia oleae Olivier, 1791 y Coccus hesperidum L.

Parasitoides sobre numerosos cóccidos, como Saissetia oleae Olivier, 1791, Ceroplastes, Coccus, Lecanium, Parthenolecanium, Pulvinaria, etc.

\begin{tabular}{llllllll}
\hline $\begin{array}{l}\text { Syrphophagus } \\
\text { aeruginosus } \\
\begin{array}{l}\text { Dalman, 1820 } \\
\text { Syrphophagus }\end{array}\end{array}$ & 0 & 0 & 0 & 4 & 0 & 4 & $\begin{array}{l}\text { Parasitoides de dípteros } \\
\text { Syrphidae. }\end{array}$ \\
$\begin{array}{l}\text { aphidivorus Mayr, } \\
1876\end{array}$ & 0 & 3 & 1 & 0 & 1 & 5 & $\begin{array}{l}\text { Parasitoides de Aphis spiraecola } \\
\text { Patch, 1914, Aphis gossypii } \\
\text { Glover, 1877 y Toxoptera } \\
\text { aurantii Boyer de F., 1841. }\end{array}$ \\
\hline
\end{tabular}

\begin{tabular}{llllllll}
\hline Syrphophagus & 0 & 2 & 0 & 0 & 0 & 2 & Parasitoides de hemípteros, como
\end{tabular}
sp.1

\begin{tabular}{|c|c|c|c|c|c|c|c|}
\hline $\begin{array}{l}\text { Syrphophagus } \\
\text { sp. } 2\end{array}$ & 0 & 3 & 1 & 1 & 0 & 5 & $\begin{array}{l}\text { 1758) y Aphididae, como Aphis } \\
\text { farinosa J.F. Gmelein, } 1790, \text { A. }\end{array}$ \\
\hline $\begin{array}{l}\text { Syrphophagus } \\
\text { sp.3 }\end{array}$ & 4 & 10 & 0 & 2 & 2 & 18 & $\begin{array}{l}\text { viburni Scopoli, 1763, } \\
\text { Hyalopterus pruni (Geoffroy, } \\
\text { 1762), Rhopalosiphum } \\
\text { nymphaeae (L., 1761), } \\
\text { Schizaphis scirpi (Mercet, 1921). } \\
\text { Parasitoide de larvas y pupas de } \\
\text { dípteros Syrphidae. }\end{array}$ \\
\hline
\end{tabular}




\begin{tabular}{|c|c|c|c|c|c|c|c|}
\hline \multirow[b]{2}{*}{ Especie } & \multicolumn{6}{|c|}{ Número de individuos por año } & \multirow[b]{2}{*}{ Hospedador } \\
\hline & 2004 & 2005 & 2006 & 2007 & 2008 & Total & \\
\hline \multicolumn{8}{|l|}{ Eulophidae } \\
\hline Aprostocetus sp.1 & 4 & 6 & 2 & 1 & 5 & 18 & \multirow{6}{*}{$\begin{array}{l}\text { Numerosos huéspedes; } \\
\text { parasitoides sobre Coccidae de } \\
\text { cecidómidos, huevos de } \\
\text { coleópteros Dytiscidae, } \\
\text { lepidópteros Lasiocampidae, etc. }\end{array}$} \\
\hline Aprostocetus sp. 2 & 4 & 0 & 0 & 0 & 0 & 4 & \\
\hline Aprostocetus sp.3 & 2 & 0 & 0 & 0 & 2 & 4 & \\
\hline Aprostocetus sp.4 & 0 & 0 & 0 & 2 & 0 & 2 & \\
\hline Aprostocetus sp.5 & 0 & 0 & 0 & 0 & 1 & 1 & \\
\hline Aprostocetus sp.6 & 0 & 0 & 2 & 0 & 0 & 2 & \\
\hline Baryscapus sp.1 & 0 & 0 & 0 & 0 & 4 & 4 & \multirow[b]{2}{*}{$\begin{array}{l}\text { Numerosos huéspedes. } \\
\text { Endoparasitoides en pupas de } \\
\text { Chrysopa sp. Parasitoides de } \\
\text { minadores foliares como } \\
\text { Gracillariidae, Yponomeutidae, } \\
\text { Lyonetiidae, Heliozelidae, etc. }\end{array}$} \\
\hline Baryscapus sp.2 & 0 & 6 & 0 & 0 & 0 & 6 & \\
\hline Chrysocharis sp.1 & 0 & 0 & 2 & 0 & 1 & 3 & \multirow{3}{*}{$\begin{array}{l}\text { Parasitoides de larvas/pupas de } \\
\text { dípteros Agromyzidae en plantas } \\
\text { herbáceas. Numerosos } \\
\text { huéspedes. }\end{array}$} \\
\hline Chrysocharis sp.2 & 0 & 0 & 0 & 2 & 0 & 2 & \\
\hline Chrysocharis sp.3 & 2 & 0 & 0 & 0 & 0 & 2 & \\
\hline $\begin{array}{l}\text { Citrostichus } \\
\text { phyllocnistoides } \\
\text { Narayanan, } 1960\end{array}$ & 2 & 4 & 6 & 4 & 0 & 16 & $\begin{array}{l}\text { Parasitoides habituales del } \\
\text { lepidóptero minador } \\
\text { Phyllocnistis citrella Stainton, } \\
1856 .\end{array}$ \\
\hline Dicladocerus sp. & 0 & 4 & 0 & 0 & 0 & 4 & $\begin{array}{l}\text { Ectoparasitoides de numerosos } \\
\text { lepidópteros, como Prays oleae } \\
\text { (Bernard, 1908), Tortrix viridana } \\
\text { L., 1758, Coleophora laricella } \\
\text { Hübner, 1817, Thaumatopoea } \\
\text { pityocampa Denis \& } \\
\text { Schiffermüller, } 1775 \text {, Panaxia } \\
\text { dominula L. 1758, etc. }\end{array}$ \\
\hline Diglyphus sp.1 & 0 & 0 & 0 & 1 & 1 & 2 & \multirow{2}{*}{$\begin{array}{l}\text { Parasitoides de dípteros } \\
\text { Agromyzidae minadores, como } \\
\text { Agromyza, Liriomyza, } \\
\text { Phytomyza, etc. }\end{array}$} \\
\hline Diglyphus sp.2 & 4 & 4 & 6 & 0 & 0 & 14 & \\
\hline Elachertus sp. & 4 & 0 & 0 & 1 & 1 & 6 & $\begin{array}{l}\text { Parasitoides de lepidópteros } \\
\text { Tortricidae, Noctuidae y } \\
\text { Coleophoridae. }\end{array}$ \\
\hline Elasmus sp.1 & 2 & 0 & 0 & 0 & 0 & 2 & Parasitoides sobre el lepidóptero \\
\hline Elasmus sp.2 & 0 & 0 & 0 & 0 & 1 & 1 & $\begin{array}{l}\text { Prays citri (Millière, 1873), en } \\
\text { Citrus sp. }\end{array}$ \\
\hline Euderomphale sp. & 0 & 0 & 0 & 0 & 1 & 1 & $\begin{array}{l}\text { Parasitoides del hemíptero } \\
\text { Aleyrodidae, Bemisia afer } \\
\text { Priesner \& Hosny, } 1934 .\end{array}$ \\
\hline
\end{tabular}




\begin{tabular}{|c|c|c|c|c|c|c|c|}
\hline \multirow[b]{2}{*}{ Especie } & \multicolumn{6}{|c|}{ Número de individuos por año } & \multirow[b]{2}{*}{ Hospedador } \\
\hline & 2004 & 2005 & 2006 & 2007 & 2008 & Total & \\
\hline Euplectrus sp.1 & 4 & 0 & 2 & 1 & 1 & 8 & Ectoparasitoides gregarios en \\
\hline Euplectrus sp.2 & 6 & 6 & 2 & 2 & 21 & 37 & $\begin{array}{l}\text { larvas de lepidópteros, } \\
\text { generalmente Noctuidae; también } \\
\text { sobre Geometridae, } \\
\text { Gracillariidae y Tortricidae. }\end{array}$ \\
\hline Hyssopus sp. & 2 & 0 & 0 & 0 & 1 & 3 & $\begin{array}{l}\text { Ectoparasitoides gregarios de } \\
\text { lepidópteros; frecuentemente } \\
\text { sobre Tortricidae, Pyralidae, } \\
\text { Coleophoridae, Gelechiidae. }\end{array}$ \\
\hline Necremnus sp. 1 & 0 & 0 & 2 & 0 & 0 & 2 & Numerosos huéspedes. \\
\hline Necremnus sp. 2 & 0 & 2 & 0 & 1 & 1 & 4 & $\begin{array}{l}\text { Parasitoides de lepidópteros } \\
\text { Coleoforidae y coleópteros } \\
\text { Chrysomelidae. }\end{array}$ \\
\hline $\begin{array}{l}\text { Neochrysocharis } \\
\text { sp. }\end{array}$ & 0 & 2 & 0 & 0 & 1 & 3 & $\begin{array}{l}\text { Parasitoides sobre lepidópteros } \\
\text { minadores, incluido Phyllocnistis } \\
\text { citrella (Stainton, 1856). }\end{array}$ \\
\hline Oomyzus sp.1 & 0 & 0 & 0 & 0 & 1 & 1 & Parasitoides frecuentes sobre \\
\hline Oomyzus sp.2 & 2 & 2 & 6 & 5 & 12 & 27 & $\begin{array}{l}\text { pupas de coleópteros } \\
\text { Coccinellidae. Endoparasitoides } \\
\text { gregarios de larvas de Chrysopa } \\
\text { spp.; ocasionalmente también de } \\
\text { Chilocorus bipustulatus L. } 1758 \text {. }\end{array}$ \\
\hline Pediobius sp.1 & 0 & 4 & 0 & 1 & 2 & 7 & Numerosos huéspedes. \\
\hline Pediobius sp.2 & 0 & 0 & 0 & 1 & 0 & 1 & Parasitoides de dípteros y \\
\hline Pediobius sp.3 & 0 & 0 & 0 & 0 & 1 & 1 & $\begin{array}{l}\text { lepidópteros minadores, de } \\
\text { himenópteros cinípidos como }\end{array}$ \\
\hline Pediobius sp.4 & 0 & 0 & 2 & 0 & 1 & 3 & $\begin{array}{l}\text { Plagiotrochus sp., en Quercus } \\
\text { ilex y } Q \text {. coccifera; } \\
\text { ocasionalmente en curculiónidos. } \\
\text { Son también hiperparasitoides de } \\
\text { lepidóteros o arácnidos, vía } \\
\text { Ichneumonoidea. }\end{array}$ \\
\hline Pnigalio sp. & 0 & 0 & 0 & 4 & 5 & 9 & $\begin{array}{l}\text { Parasitoides de numerosos } \\
\text { insectos minadores, como } \\
\text { Gracillariidae, Elachistidae, } \\
\text { Nepticulidae, Lyonetidae, } \\
\text { Tischeriidae, Agromyzidae, } \\
\text { Curculionidae, etc. En Citrus sp., } \\
\text { citado sobre Phyllocnistis citrella } \\
\text { (Stainton, 1856). }\end{array}$ \\
\hline Tamarixia sp. & 0 & 2 & 0 & 0 & 0 & 2 & $\begin{array}{l}\text { Parasitoides frecuentes del } \\
\text { hemíptero Psyllidae Trioza } \\
\text { remota Foerster, 1848; a menudo } \\
\text { en Quercus sp. }\end{array}$ \\
\hline
\end{tabular}




\begin{tabular}{|c|c|c|c|c|c|c|c|}
\hline \multirow[b]{2}{*}{ Especie } & \multicolumn{6}{|c|}{ Número de individuos por año } & \multirow[b]{2}{*}{ Hospedador } \\
\hline & 2004 & 2005 & 2006 & 2007 & 2008 & Total & \\
\hline Tetrastichus sp.1 & 0 & 0 & 0 & 0 & 9 & 9 & \multirow{3}{*}{$\begin{array}{l}\text { Parasitoide de diversos } \\
\text { coleópteros y dípteros. También } \\
\text { se ha citado parasitando al } \\
\text { lepidóptero Plutella xylostella } \\
\text { (L., 1758). }\end{array}$} \\
\hline Tetrastichus sp. 2 & 0 & 0 & 0 & 1 & 0 & 1 & \\
\hline Tetrastichus sp.3 & 0 & 0 & 0 & 0 & 1 & 1 & \\
\hline \multicolumn{8}{|l|}{ Eupelmidae } \\
\hline Anastatus sp. & 6 & 4 & 4 & 0 & 4 & 18 & $\begin{array}{l}\text { Parasitoides de huevos de } \\
\text { lepidópteros Lasiocampidae, } \\
\text { Nymphalidae, Papilionidae, etc.; } \\
\text { también sobre huevos de } \\
\text { hemípteros Pentatomidae y } \\
\text { Coreidae. }\end{array}$ \\
\hline
\end{tabular}

\section{Eurytomidae}

\begin{tabular}{|c|c|c|c|c|c|c|c|}
\hline Aximopsis sp.1 & 2 & 0 & 0 & 0 & 0 & 2 & Se ha mencionado como \\
\hline Aximopsis sp.2 & 0 & 0 & 0 & 0 & 1 & 1 & $\begin{array}{l}\text { parasitoides en nidos de los } \\
\text { himenópteros Aculeata Prosopis, } \\
\text { Ceratina, Trypoxylon, Crabro, } \\
\text { etc.; y también en agallas de } \\
\text { Cinípidae Diplolepis sp., en Rosa } \\
\text { sp. }\end{array}$ \\
\hline Eurytoma sp. & 0 & 2 & 0 & 1 & 1 & 8 & $\begin{array}{l}\text { Numerosos huéspedes. Se ha } \\
\text { mencionado como parasitoides } \\
\text { sobre el lepidóptero Phyllocnistis } \\
\text { citrella (Stainton, 1856). }\end{array}$ \\
\hline Sycophila sp. & 0 & 2 & 0 & 0 & 0 & 2 & $\begin{array}{l}\text { Parasitoides en agallas de } \\
\text { himenópteros Cinipidae, en } \\
\text { Quercus sp. }\end{array}$ \\
\hline
\end{tabular}

\section{Mymaridae}

\begin{tabular}{|c|c|c|c|c|c|c|c|}
\hline Gonatocerussp. & 0 & 0 & 0 & 1 & 0 & 1 & $\begin{array}{l}\text { Parasitoides de huevos de } \\
\text { hemípteros Cicadellidae y } \\
\text { Membracidae. }\end{array}$ \\
\hline Polynema sp. & 0 & 2 & 0 & 0 & 3 & 5 & $\begin{array}{l}\text { Parasitoides de huevos de } \\
\text { hemípteros Cicadellidae, } \\
\text { Miridae, Nabidae e Issidae. }\end{array}$ \\
\hline \multicolumn{8}{|l|}{ Perilampidae } \\
\hline Perilampus sp.1 & 0 & 0 & 0 & 1 & 0 & 1 & \multirow{3}{*}{$\begin{array}{l}\text { Parasitoides de himenópteros } \\
\text { Tenthredinidae, de lepidópteros } \\
\text { Tortricidae, Pyralidae, } \\
\text { Lymantriidae y Gelechiidae; } \\
\text { opcionalmente, hiperparasitoides. } \\
\text { Parasitoides también de } \\
\text { neurópteros: Chrysopa } \text { sp. }\end{array}$} \\
\hline Perilampus sp.2 & 2 & 0 & 0 & 1 & 1 & 4 & \\
\hline Perilampus sp.3 & 0 & 0 & 0 & 1 & 0 & 1 & \\
\hline
\end{tabular}




\begin{tabular}{|c|c|c|c|c|c|c|c|}
\hline \multirow[b]{2}{*}{ Especie } & \multicolumn{6}{|c|}{ Número de individuos por año } & \multirow[b]{2}{*}{ Hospedador } \\
\hline & 2004 & 2005 & 2006 & 2007 & 2008 & Total & \\
\hline \multicolumn{8}{|l|}{ Pteromalidae } \\
\hline $\begin{array}{l}\text { Asaphes } \\
\text { suspensus Nees, } \\
1834\end{array}$ & 2 & 0 & 0 & 2 & 1 & 5 & $\begin{array}{l}\text { Hiperparasitoides sobre } \\
\text { numerosos áfidos, via } \\
\text { Braconidae Aphidiinae. }\end{array}$ \\
\hline $\begin{array}{l}\text { Asaphes vulgaris } \\
\text { Walker, } 1834\end{array}$ & 28 & 36 & 128 & 193 & 82 & 467 & $\begin{array}{l}\text { Hiperparasitoides sobre } \\
\text { numerosos áfidos, via } \\
\text { Braconidae Aphidiinae; } \\
\text { opcionalmente, sobre Syrphidae } \\
\text { depredadores de áfidos. }\end{array}$ \\
\hline Catolaccus sp. & 4 & 0 & 0 & 1 & 0 & 1 & $\begin{array}{l}\text { Hiperparasitoides de } \\
\text { lepidópteros, via Braconidae del } \\
\text { género Apanteles sp.; también } \\
\text { parasitoides de neurópteros del } \\
\text { género Chrysopa. }\end{array}$ \\
\hline Chlorocytus sp. & 4 & 2 & 0 & 1 & 1 & 8 & $\begin{array}{l}\text { Numerosos huéspedes. } \\
\text { Parasitoides sobre dípteros } \\
\text { Agromyzidae, himenópteros } \\
\text { Cephidae Aylacini, coleópteros } \\
\text { Cerambycidae, Curculionidae, } \\
\text { etc. }\end{array}$ \\
\hline Conomorium sp. & 4 & 0 & 0 & 1 & 0 & 5 & $\begin{array}{l}\text { Parasitoides de pupas de } \\
\text { lepidópteros de las familias } \\
\text { Arctiidae, Geometridae, } \\
\text { Gracillariidae, Lasiocampidae, } \\
\text { Lyonetiidae, Noctuidae, } \\
\text { Notodontidae y Tineidae. }\end{array}$ \\
\hline $\begin{array}{l}\text { Cyrtogaster } \\
\text { degener Walker, } \\
1833\end{array}$ & 18 & 12 & 44 & 321 & 186 & 581 & $\begin{array}{l}\text { Parasitoides de dípteros } \\
\text { minadores Agromyzidae; } \\
\text { también en otras familias como } \\
\text { Chloropidae, Drosophilidae, } \\
\text { Lonchopteridae, Tephritidae, etc. }\end{array}$ \\
\hline Dinarmus sp. & 2 & 2 & 0 & 0 & 0 & 4 & $\begin{array}{l}\text { Parasitoides de coleópteros de la } \\
\text { familia Bruchidae, en semillas de } \\
\text { papilionáceas. }\end{array}$ \\
\hline Eunotus sp. & 0 & 0 & 0 & 1 & 0 & 1 & $\begin{array}{l}\text { Parasitoides sobre hemípteros } \\
\text { Coccidae, en gramíneas. }\end{array}$ \\
\hline $\begin{array}{l}\text { Gastrancistrus } \\
\text { sp.1 }\end{array}$ & 0 & 0 & 0 & 0 & 1 & 1 & $\begin{array}{l}\text { Parasitoides de agallas de } \\
\text { himenópteros Cecidomiiddae. }\end{array}$ \\
\hline $\begin{array}{l}\text { Gastrancistrus } \\
\mathrm{sp} .2\end{array}$ & 0 & 2 & 0 & 1 & 1 & 4 & \\
\hline Homoporus sp. & 0 & 0 & 0 & 1 & 0 & 1 & $\begin{array}{l}\text { Parasitoides de himenópteros, } \\
\text { principalmente de Eurytomidae, } \\
\text { Cynipidae, etc. }\end{array}$ \\
\hline
\end{tabular}




\begin{tabular}{|c|c|c|c|c|c|c|c|}
\hline \multirow[b]{2}{*}{ Especie } & \multicolumn{6}{|c|}{ Número de individuos por año } & \multirow[b]{2}{*}{ Hospedador } \\
\hline & 2004 & 2005 & 2006 & 2007 & 2008 & Total & \\
\hline Indeterminada & 0 & 0 & 0 & 2 & 0 & 2 & \\
\hline Mesopolobus sp.1 & 4 & 0 & 0 & 17 & 0 & 21 & \multirow{4}{*}{$\begin{array}{l}\text { Numerosos huéspedes. Se } \\
\text { pueden destacar como } \\
\text { parasitoides de los himenópteros } \\
\text { Cecidomiidae Oligotrophus } \\
\text { juniperinus L., } 1758 \text { y Taxomyia } \\
\text { taxi Inchbald, 1861. También } \\
\text { como parasitoides de Cynipidae } \\
\text { en Quercus sp. }\end{array}$} \\
\hline Mesopolobus sp.2 & 0 & 0 & 0 & 3 & 0 & 3 & \\
\hline Mesopolobus sp. 3 & 4 & 8 & 0 & 0 & 0 & 12 & \\
\hline Mesopolubus sp.4 & 0 & 0 & 0 & 1 & 0 & 1 & \\
\hline Metastenus sp. & 0 & 0 & 0 & 0 & 1 & 1 & $\begin{array}{l}\text { Numerosos huéspedes. } \\
\text { Principalmente, parasitoides de } \\
\text { coleópteros Coccinellidae } \\
\text { Scymninae, Scymnus sp., S. } \\
\text { apetzi Mulsant, } 1846, \text { S. impexus } \\
\text { Mulsant, } 1850 \text { y Cryptolaemus } \\
\text { montrouzieri Mulsant, } 1853 \text {. }\end{array}$ \\
\hline Miscogaster sp.1 & 0 & 0 & 0 & 1 & 0 & 1 & Numerosos huéspedes. \\
\hline Miscogaster sp.2 & 0 & 0 & 0 & 0 & 1 & 1 & $\begin{array}{l}\text { Parasitoides de dípteros } \\
\text { minadores, como Phytobia, } \\
\text { Agromyza, Liriomyza, } \\
\text { Napomyza, etc. }\end{array}$ \\
\hline $\begin{array}{l}\text { Pachycrepoideus } \\
\text { vindemmiae } \\
\text { Rondani, } 1875\end{array}$ & 4 & 0 & 0 & 0 & 1 & 5 & $\begin{array}{l}\text { Parasitoides de numerosos } \\
\text { dípteros; entre ellos, del } \\
\text { Tephrytidae Ceratitis capitata } \\
\text { (Wiedemann, 1824), pero } \\
\text { actuando también como } \\
\text { hiperparasitoides. }\end{array}$ \\
\hline
\end{tabular}

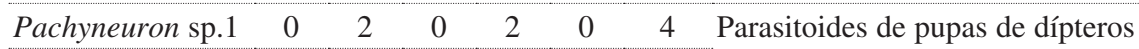

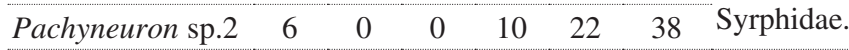

\begin{tabular}{llllllll}
\hline Pachyneuron & 0 & 4 & 0 & 0 & 3 & 7 & Hiperparasitoides de pulgones a
\end{tabular} aphidis Bouché, través de Braconidae Aphidiinae: 1834 sobre Aphidius Nees, 1819, Diaeretiella Stary, 1960, Lysiphlebus Forster, 1862, Praon Haliday, 1833, Trioxys Haliday, 1833.

$\begin{array}{llllllll}\text { Pachyneuron } & 16 & 28 & 49 & 274 & 129 & 496 & \text { Numerosos huéspedes. }\end{array}$ formosum Walker, Parasitoides de pupas de dípteros 1833

Syrphidae, Episyrphus, Sphaerophoria, Syrphus, Xanthandrus; opcionalmente, hiperparasitoides en áfidos vía Braconidae Aphidiinae. 


\begin{tabular}{|c|c|c|c|c|c|c|c|}
\hline \multirow[b]{2}{*}{ Especie } & \multicolumn{6}{|c|}{ Número de individuos por año } & \multirow[b]{2}{*}{ Hospedador } \\
\hline & 2004 & 2005 & 2006 & 2007 & 2008 & Total & \\
\hline $\begin{array}{l}\text { Pachyneuron } \\
\text { groenlandicum } \\
\text { Holmgren, } 1872\end{array}$ & 0 & 0 & 0 & 3 & 1 & 4 & $\begin{array}{l}\text { Parasitoides de pupas de dípteros } \\
\text { Syrphidae. }\end{array}$ \\
\hline $\begin{array}{l}\text { Pseudocatolaccus } \\
\text { sp. }\end{array}$ & 0 & 2 & 0 & 1 & 0 & 3 & $\begin{array}{l}\text { Parasitoides de agallas de } \\
\text { dípteros Cecidomyidae, a } \\
\text { menudo Asphondylia sp., en } \\
\text { plantas herbáceas. }\end{array}$ \\
\hline Psilocera sp. & 0 & 0 & 0 & 0 & 2 & 2 & $\begin{array}{l}\text { Género parasitoide; posiblemente } \\
\text { sobre coleópteros en el suelo y } \\
\text { sobre Chrysomelidae. }\end{array}$ \\
\hline Pteromalus sp. 1 & 0 & 0 & 0 & 1 & 0 & 1 & Numerosos huéspedes. \\
\hline Pteromalus sp. 2 & 0 & 4 & 0 & 3 & 0 & 7 & Parasitoides de coleópteros \\
\hline Pteromalus sp. 3 & 0 & 2 & 0 & 0 & 1 & 3 & $\begin{array}{l}\text { Apionidae, Bruchidae, } \\
\text { Curculionidae, himenópteros } \\
\text { Eurytomidae y dípteros } \\
\text { Cecidomyiidae, en plantas } \\
\text { papilionáceas, y de Tephritidae, } \\
\text { en Artemisia sp. Algunos citados } \\
\text { como parasitoides sobre Prays } \\
\text { citri (Millière, 1873) y } \\
\text { Phyllocnistis citrella Stainton, } \\
1856 .\end{array}$ \\
\hline Rhicnocoelia sp. & 0 & 0 & 0 & 1 & 1 & 2 & $\begin{array}{l}\text { Posiblemente, parasitoides de } \\
\text { dípteros minadores en plantas } \\
\text { herbáceas. }\end{array}$ \\
\hline Rohatina sp. & 0 & 2 & 0 & 0 & 0 & 2 & $\begin{array}{l}\text { Género con biología desconocida; } \\
\text { citado en Madrid y Cantabria. }\end{array}$ \\
\hline Scutellista sp. & 0 & 4 & 0 & 0 & 0 & 4 & $\begin{array}{l}\text { Género con parasitoides sobre } \\
\text { diversos hemípteros; en especial, } \\
\text { Asterolecaniidae (Asterolecanium, } \\
\text { Cerococcus), Coccidae } \\
\text { (Ceroplastes, Ceroplastodes, } \\
\text { Parasaissetia, Saissetia) y } \\
\text { Pseudococcidae (Ferrisa). }\end{array}$ \\
\hline $\begin{array}{l}\text { Scutellista } \\
\text { caerulea } \\
\text { Fonscolombe, } \\
1832\end{array}$ & 8 & 16 & 10 & 0 & 28 & 62 & $\begin{array}{l}\text { Parasitoides de hemípteros } \\
\text { Coccidae y Pseudococcidae, que } \\
\text { actúan como depredadores de } \\
\text { huevos y larvas. En Citrus sp., } \\
\text { actúan como un } \\
\text { pseudoparasitoides de Saissetia } \\
\text { oleae (Olivier, 1791), } \\
\text { Ceroplastes sinensis Del Guercio, } \\
\text { 1900, C. floridensis Comstock, } \\
1881 \text { y C. rusci (L., 1758). }\end{array}$ \\
\hline
\end{tabular}




\begin{tabular}{|c|c|c|c|c|c|c|c|}
\hline \multirow[b]{2}{*}{ Especie } & \multicolumn{6}{|c|}{ Número de individuos por año } & \multirow[b]{2}{*}{ Hospedador } \\
\hline & 2004 & 2005 & 2006 & 2007 & 2008 & Total & \\
\hline Spalangia sp. & 0 & 2 & 0 & 0 & 0 & 2 & $\begin{array}{l}\text { Género con ectoparásitos de } \\
\text { pupas de dípteros. }\end{array}$ \\
\hline Sphegigaster sp. & 0 & 0 & 0 & 0 & 2 & 2 & $\begin{array}{l}\text { Parasitoides de dipteros, a } \\
\text { menudo Agromyzidae } \\
\text { minadores. }\end{array}$ \\
\hline Stenomalina sp. & 0 & 0 & 0 & 1 & 0 & 1 & $\begin{array}{l}\text { Numerosos huéspedes. } \\
\text { Parasitoides de dípteros } \\
\text { Agromyzidae y Chloropidae, en } \\
\text { plantas herbáceas. }\end{array}$ \\
\hline Systasis sp. & 0 & 2 & 0 & 0 & 0 & 2 & $\begin{array}{l}\text { Parasitoides del díptero } \\
\text { Cecidomyiidae Contarinia } \\
\text { medicaginis Kieffer, } 1895 .\end{array}$ \\
\hline Toxeumorpha sp. & 0 & 0 & 2 & 0 & 2 & 4 & $\begin{array}{l}\text { Parasitoides del lepidóptero } \\
\text { Tortricidae Cryptophlebia } \\
\text { leucotreta Meyrick, 1913, } \\
\text { introducido en Citrus sp., y del } \\
\text { Lyonetiidae Leucoptera sp., en } \\
\text { Coffea } \text { sp. }\end{array}$ \\
\hline Trichomalus sp.1 & 0 & 0 & 0 & 0 & 1 & 1 & Numerosos huéspedes. Género a \\
\hline Trichomalus sp.2 & 0 & 0 & 0 & 3 & 0 & 3 & menudo con parasitoides sobre \\
\hline Trichomalus sp.3 & 4 & 0 & 2 & 2 & 1 & 9 & $\begin{array}{l}\text { coleópteros Curculionidae; } \\
\text { también sobre dípteros } \\
\text { Chloropidae y otros grupos. }\end{array}$ \\
\hline
\end{tabular}

\section{Signiphoridae}

$\begin{array}{llllllll}\text { Chartocerus sp. } & 2 & 0 & 0 & 0 & 0 & 2 & \text { Posiblemente, parasitoides de }\end{array}$ hemípteros Peudococcidae, Aleyrodidae o hiperparasitoides con otras especies.

\section{Tetracampidae}

Epiclerus sp. $\begin{array}{lllllll}2 & 0 & 0 & 1 & 1 & 4 & \text { Parasitoides de dípteros }\end{array}$ Agromycidae, principalmente, Liriomyza y Phytomyza.

\section{Torymidae}

Megastigmus sp. $\quad \begin{array}{lllllll}0 & 2 & 0 & 0 & 0 & 2 & \text { Parasitoides de diversos grupos. }\end{array}$

Algunos son fitófagos de semillas de Pistacia lentiscus L., P.terebinthus L.

\begin{tabular}{|c|c|c|c|c|c|c|c|}
\hline $\begin{array}{l}\text { Monodontomerus } \\
\text { sp. }\end{array}$ & 0 & 0 & 0 & 0 & 0 & 2 & $\begin{array}{l}\text { Parasitoides de numerosas } \\
\text { especies de himenópteros } \\
\text { Aculeata: Megachile, Osmia, } \\
\text { Chalicodoma, Xylocopa, } \\
\text { Sceliphron, Eumenes, etc. }\end{array}$ \\
\hline
\end{tabular}




\begin{tabular}{|c|c|c|c|c|c|c|c|}
\hline \multirow[b]{2}{*}{ Especie } & \multicolumn{6}{|c|}{ Número de individuos por año } & \multirow[b]{2}{*}{ Hospedador } \\
\hline & 2004 & 2005 & 2006 & 2007 & 2008 & Total & \\
\hline Podagrion sp. & 0 & 0 & 0 & 0 & 1 & 1 & $\begin{array}{l}\text { Parasitoides de ootecas de } \\
\text { Mantis religiosa L. } 1758 \text {. }\end{array}$ \\
\hline Torymus sp. & 0 & 0 & 0 & 0 & 1 & 1 & $\begin{array}{l}\text { Numerosos huéspedes. } \\
\text { Parasitoides en agallas de } \\
\text { dípteros Cecidomyiidae; se ha } \\
\text { mencionado sobre Braueriella } \\
\text { phillyreae F. Low, } 1877 \text { en } \\
\text { Phillyrea sp., sobre Asphondylia } \\
\text { sarothamni Loew, } 1850 \text { en } \\
\text { Cytisus scoparius L., sobre } \\
\text { Stictodiplosis scrophulariae en } \\
\text { Scrophularia sp., etc. }\end{array}$ \\
\hline
\end{tabular}

Trichogrammatidae

$\begin{array}{llllllll}\text { Pseudoligosita sp. } & 0 & 0 & 0 & 0 & 1 & 1 & \text { Familia con endoparásitos en }\end{array}$ huevos de lepidópteros, hemípteros, coleópteros y tisanópteros.

\section{Bethylidae}

$\begin{array}{llllllcl}\text { Bethylus sp.1 } & 8 & 2 & 0 & 3 & 1 & 14 & \text { Género con parasitoides sobre } \\ \text { Bethylus sp.2 } & 0 & 0 & 6 & 1 & 0 & 7 & \begin{array}{l}\text { larvas de lepidópteros } \\ \text { Gelechiidae y Noctuidae. }\end{array}\end{array}$

\section{Chrysididae}

\begin{tabular}{llllllll}
\hline $\begin{array}{l}\text { Pseudomalus } \\
\text { auratus Linnaeus, } \\
1758\end{array}$ & 4 & 0 & 0 & 0 & 0 & 4 & $\begin{array}{l}\text { Parasitoides de himenópteros } \\
\text { Sphecidae Pemphredoninae y } \\
\text { Larrinae. }\end{array}$
\end{tabular}

\begin{tabular}{llllllll}
\hline Dryinidae & & & & & & & \\
\hline Gonatopus sp. & 0 & 0 & 0 & 0 & 1 & 1 & $\begin{array}{l}\text { Endoparasitoides de hemípteros } \\
\text { Cicadellidae y Delphacidae. }\end{array}$
\end{tabular}

\section{Cynipidae}

$\begin{array}{llllllll}\text { Phanacis sp. } & 0 & 2 & 0 & 0 & 0 & 2 & \text { Género gallícola sobre plantas }\end{array}$ herbáceas, Centaurea, Picris, Hypochoeris, Silybum, etc. (Nieves-Aldrey, 2008; NievesAldrey et al., 2008).

$\begin{array}{llllllll}\text { Plagiotrochus sp. } & 0 & 0 & 0 & 1 & 0 & 1 & \begin{array}{l}\text { Especies gallícolas en Quercus } \\ \text { ilex L. y Quercus coccifera L. }\end{array}\end{array}$

\section{Figitidae}

$\begin{array}{llllllll}\text { Alloxysta arcuata } & 0 & 2 & 0 & 0 & 0 & 2 & \text { Género con hiperparasitoides de }\end{array}$ (Kieffer, 1902) áfidos, via Braconidae Aphidiinae; opc. también via Aphelinidae (Ferrer-Suay et al., 2012). 


\begin{tabular}{c}
\hline \\
Especie
\end{tabular}$\frac{\text { Número de individuos por año }}{20042005200620072008 \text { Total }}$

\begin{tabular}{llllllll}
\hline Alloxysta brevis & 6 & 12 & 2 & 1 & 6 & 27 & Hiperparasitoides sobre Aphis
\end{tabular}

(Thomson, 1862)

craccivora Koch, 1854 en

Medicago sativa L.,

Rhopalosiphum padi Koch, 1854

en Zea mays L., y áfidos Aphis,

Myzus, Dysaphis, etc. (Ferrer-

Suay et al., 2012).

\begin{tabular}{llllllll}
\hline Alloxysta citripes & 0 & 0 & 2 & 1 & 0 & 3 & Sobre Aphididae, Tuberculoides,
\end{tabular}

Thomson, 1862

Pterocallis, Drepanosiphum, vía

Trioxys, Aphelinus (Ferrer-Suay

et al., 2011 y 2012).

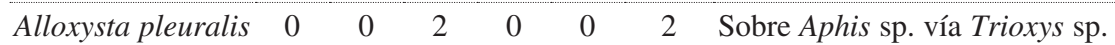

Cameron, 1879 (Ferrer-Suay et al., 2012).

$\begin{array}{llllllll}\text { Apocharips } & 0 & 2 & 2 & 0 & 0 & 4 & \text { Género con parasitoides de }\end{array}$

trapezoidea Psylloidea (Nieves-Aldrey et al.,

Hartig, 1841 2003; Ferrer-Suay et al., 2012).

$\begin{array}{lllllllll}\text { Callaspidia notata } & 0 & 4 & 0 & 1 & 4 & 9 & \text { Género con parasitoides de }\end{array}$

Fonscolombe,

1832

larvas y pupas de Syrphidae

(Ros-Farré \& Pujade-Villar, 2009).

$\begin{array}{llllllll}\text { Kleidotoma } \text { sp. } & 2 & 4 & 1 & 0 & 1 & 8 & \text { Género con endoparasitoides de }\end{array}$ dípteros ciclorrafos (Nieves-

Aldrey et al., 2003).

\begin{tabular}{rllllllll}
\hline Lonchidia sp. & 2 & 0 & 0 & 0 & 1 & 3 & $\begin{array}{l}\text { Biología desconocida; } \\
\text { parasitoides de díptera (Ros- } \\
\text { Farré \& Pujade-Villar, 1997). }\end{array}$ \\
& & & & & &
\end{tabular}

$\begin{array}{llllllll}\text { Melanips sp.1 } & 2 & 0 & 0 & 2 & 11 & 15 & \text { Género con parasitoides de }\end{array}$

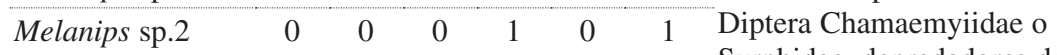

Syrphidae, depredadores de áfidos (Ros-Farré \& PujadeVillar, 1997; Nieves-Aldrey et al., 2003).

\begin{tabular}{lllllllll}
\hline Phaenoglyphis & 4 & 4 & 0 & 1 & 1 & 10 & Hiperparasitoides de áfidos, via
\end{tabular} villosa Hartig, Braconidae Aphidiinae (Suay1841 Cano et al., 1998; Ferrer-Suay et al., 2012).

$\begin{array}{llllllll}\text { Trybliographa } \text { sp. } & 0 & 0 & 0 & 0 & 1 & 1 & \text { Sobre Diptera Anthomyiidae, }\end{array}$ Lonchaeidae y Muscidae (Fontal \& Nieves-Aldrey, 2004;

Forshage \& Nordlander, 2008).

\begin{tabular}{llllllll}
\hline Xyalaspis sp. & 2 & 0 & 0 & 0 & 4 & 6 & Parasitoides de Neuroptera
\end{tabular} Chrysopidae (Ros-Farré \& Pujade-Villar, 1997) 


\begin{tabular}{|c|c|c|c|c|c|c|c|}
\hline \multirow[b]{2}{*}{ Especie } & \multicolumn{6}{|c|}{ Número de individuos por año } & \multirow[b]{2}{*}{ Hospedador } \\
\hline & 2004 & 2005 & 2006 & 2007 & 2008 & Total & \\
\hline \multicolumn{8}{|l|}{ Braconidae } \\
\hline Adelius sp. & 0 & 0 & 2 & 0 & 0 & 2 & $\begin{array}{l}\text { Género con endoparasitoides de } \\
\text { lepidópteros minadores de los } \\
\text { géneros Phyllonorycter y } \\
\text { Nepticula. }\end{array}$ \\
\hline Aleiodes sp.1 & 0 & 0 & 0 & 0 & 2 & 2 & Numerosos hospedadores. \\
\hline Aleiodes sp.2 & 0 & 0 & 0 & 0 & 2 & 2 & $\begin{array}{l}\text { Género con parasitoides de } \\
\text { lepidópteros Noctuidae, } \\
\text { Lymantriidae, Lasiocampidae, } \\
\text { Notodontidae, Arctiidae, } \\
\text { Geometridae, Sphingidae, etc. }\end{array}$ \\
\hline Alysia sp. & 0 & 0 & 0 & 0 & 1 & 1 & $\begin{array}{l}\text { Parasitoides de numerosos } \\
\text { dípteros: Calliphoridae, como } \\
\text { Calliphora sp., Lucilia sp., } \\
\text { Chrysomya sp., el Anthomyidae } \\
\text { Delia } \text { sp., el Muscidae Musca } \\
\text { domestica, etc. }\end{array}$ \\
\hline Aphaereta sp. & 0 & 0 & 2 & 0 & 0 & 2 & $\begin{array}{l}\text { Género con parasitoides de } \\
\text { numerosos dípteros; a menudo, } \\
\text { en Sarcophagidae. }\end{array}$ \\
\hline Aphidius sp. & 4 & 0 & 0 & 0 & 0 & 4 & $\begin{array}{l}\text { Parasitoides de los áfidos } \\
\text { Chaetosiphon sp., Longicaudus } \\
\text { sp., (en rosáceas), y también } \\
\text { sobre Capitophorus sp., } \\
\text { Macrosiphoniella sp., (en } \\
\text { Artemisia). }\end{array}$ \\
\hline $\begin{array}{l}\text { Aphidius cf. ervi } \\
\text { (Haliday, 1834) }\end{array}$ & 0 & 0 & 2 & 0 & 1 & 3 & $\begin{array}{l}\text { Parasitoides sobre numerosos } \\
\text { áfidos, especialmente } \\
\text { Acyrthosiphon pisum (Harris, } \\
\text { 1776) en leguminosas (también } \\
\text { sobre Sitobion avenae } \\
\text { [Fabricius]) y Diuraphis noxia } \\
\text { (Kurdjumov, 1913) en } \\
\text { gramíneas. También sobre } \\
\text { Acyrtosiphon sp., Aulacorthum, } \\
\text { Brachycaudus, Capitophorus, } \\
\text { Macrosiphum, Macrolophium, } \\
\text { Metopolophium dirhodum, } \\
\text { Myzus persicae (Sulzer, 1776), } \\
\text { etc. }\end{array}$ \\
\hline
\end{tabular}




\begin{tabular}{ccc}
\hline & \multicolumn{2}{c}{ Número de individuos por año } \\
\cline { 2 - 4 } Especie & 20042005200620072008 Total
\end{tabular}

Aphidius cf. matricariae

(Haliday, 1834)

$\begin{array}{llllll}0 & 0 & 2 & 0 & 0 & 2\end{array}$

\section{Hospedador}

Parasitoides sobre diversos hemípteros Aphididae, como Myzus persicae (Sulzer, 1776), Aphis pomi De Geer, 1773, Aphis gossypii Glover, 1877, Macrosiphum euphorbiae (Thomas, 1878), Aulacorthum solani Kaltenbach, 1843, Capitophorus carduinus Walker, 1850, Ovatus crataegarius Walker, 1850, etc. Citado en Citrus sp., sobre Myzus persicae (Sulzer, 1776) y Toxoptera aurantii Boyer de F., 1841.

\begin{tabular}{|c|c|c|c|c|c|c|c|}
\hline Aspilota sp.1 & 4 & 0 & 10 & 8 & 4 & 26 & Género con parasitoides de \\
\hline Aspilota $\mathrm{sp} .2$ & 2 & 0 & 0 & 0 & 2 & 4 & $\begin{array}{l}\text { dípteros Anthomyiidae, Phoridae } \\
\text { y Platypezidae. }\end{array}$ \\
\hline $\begin{array}{l}\text { Binodoxys } \\
\text { angelicae Haliday, } \\
1833\end{array}$ & 6 & 2 & 0 & 0 & 0 & 8 & $\begin{array}{l}\text { Parasitoides de homópteros } \\
\text { Aphidindae: Aphis, } \\
\text { Brachycaudus, Myzus, } \\
\text { Toxoptera, etc. En cítricos } \\
\text { parasitoides de Aphis spiraecola } \\
\text { Patch, } 1914 \text { y Aphis gossypii } \\
\text { Glover, } 1877 .\end{array}$ \\
\hline
\end{tabular}

\begin{tabular}{|lcccccc|}
\hline Blacus sp. 1 & 0 & 0 & 10 & 0 & 0 & 10 \\
\hline Blacus sp. 2 & 0 & 0 & 4 & 41 & 0 & 45 \\
\hline Blacus sp. 3 & 6 & 6 & 4 & 0 & 35 & 51 \\
\hline
\end{tabular}

Numerosos huéspedes. Endoparasitoides de larvas de coleópteros Anobiidae, Curculionidae, Scolytidae, Nitidulidae, Melyridae, Staphylinidae, etc.

\begin{tabular}{|c|c|c|c|c|c|c|c|}
\hline Bracon sp. & 0 & 0 & 2 & 0 & 0 & 2 & $\begin{array}{l}\text { Género con biología muy } \\
\text { variada. }\end{array}$ \\
\hline Choeras sp. & 0 & 0 & 0 & 1 & 0 & 1 & $\begin{array}{l}\text { Parasitoides de varios } \\
\text { lepidópteros, incluido el } \\
\text { Torticidae Cacoecimorpha } \\
\text { pronubana Hübner, } 1799 \text { en } \\
\text { Citrus sinensis Osbeck. }\end{array}$ \\
\hline Dacnusa sp. & 0 & 0 & 0 & 1 & 0 & 1 & $\begin{array}{l}\text { Género con parasitoides de } \\
\text { dípteros, normalmente, } \\
\text { Agromyzidae minadores. }\end{array}$ \\
\hline Dinotrema sp. 1 & 0 & 0 & 0 & 4 & 3 & 7 & Numerosos huéspedes. Género \\
\hline Dinotrema sp. 2 & 2 & 2 & 0 & 2 & 2 & 8 & $\begin{array}{l}\text { con parasitoides de dípteros } \\
\text { Anthomyiidae, Phoridae, } \\
\text { Platypezidae. }\end{array}$ \\
\hline
\end{tabular}




\begin{tabular}{|c|c|c|c|c|c|c|c|}
\hline \multirow[b]{2}{*}{ Especie } & \multicolumn{6}{|c|}{ Número de individuos por año } & \multirow[b]{2}{*}{ Hospedador } \\
\hline & 2004 & 2005 & 2006 & 2007 & 2008 & Total & \\
\hline Diolcogaster sp. & 0 & 2 & 0 & 0 & 0 & 2 & $\begin{array}{l}\text { Parasitoides de lepidópteros, } \\
\text { principalmente, Noctuidae, } \\
\text { Geometridae, etc. }\end{array}$ \\
\hline Diospilus sp. & 0 & 0 & 0 & 1 & 0 & 1 & $\begin{array}{l}\text { Género con endoparasitoides de } \\
\text { coleópteros Anobiidae, } \\
\text { Nitidulidae, Curculionidae, etc. }\end{array}$ \\
\hline $\begin{array}{l}\text { Ephedrus persicae } \\
\text { Froggatt, } 1904\end{array}$ & 2 & 0 & 0 & 0 & 0 & 2 & $\begin{array}{l}\text { En Citrus sp., citada sobre Aphis } \\
\text { gossypii Glover, 1877, A. } \\
\text { craccivora Koch, 1854, Aphis } \\
\text { spiraecola Patch, 1914, Myzus } \\
\text { persicae (Sulzer, 1776) y } \\
\text { Toxoptera aurantii Boyer de F., } \\
1841 .\end{array}$ \\
\hline Glyptapanteles sp. & 0 & 0 & 0 & 1 & 1 & 2 & $\begin{array}{l}\text { Numerosos huéspedes. } \\
\text { Parasitoides de lepidópteros; } \\
\text { frecuentemente, Noctuidae y } \\
\text { también Arctiidae, Geometridae, } \\
\text { Limantriidae, Plutellidae, } \\
\text { Gluphipterygidae. }\end{array}$ \\
\hline Habrobracon sp. & 0 & 0 & 0 & 0 & 2 & 2 & $\begin{array}{l}\text { Parasitoides del lepidóptero } \\
\text { Yponomeutidae Prays citri } \\
\text { (Millière, 1873). }\end{array}$ \\
\hline Hormius sp. & 2 & 2 & 0 & 5 & 1 & 10 & $\begin{array}{l}\text { Género con parasitoides de } \\
\text { numerosos lepidópteros: } \\
\text { Gelechiidae, Pyraustidae, } \\
\text { Coelophoridae, Tortricidae, etc. }\end{array}$ \\
\hline $\begin{array}{l}\text { Lysiphlebus } \\
\text { testaceipes } \\
\text { Cresson, } 1880\end{array}$ & 8 & 0 & 6 & 0 & 11 & 25 & $\begin{array}{l}\text { Parasitoides de hemípteros } \\
\text { Aphididae: Aphis, Brachycaudus, } \\
\text { Myzus, Rhopalosiphum, } \\
\text { Toxoptera; en Citrus sp., sobre } \\
\text { Aphis gossypii Glover, 1877, } \\
\text { Aphis spiraecola } \text { Patch, 1914, A. } \\
\text { craccivora Koch, 1854, Myzus } \\
\text { persicae (Sulzer, 1776) y } \\
\text { Toxoptera aurantii Boyer de F., } \\
\text { 1841. }\end{array}$ \\
\hline Meteorus sp. & 0 & 0 & 0 & 0 & 1 & 1 & $\begin{array}{l}\text { Parasitoides de numerosos } \\
\text { lepidópteros, principalmente, } \\
\text { Noctuidae. }\end{array}$ \\
\hline Mirax sp. & 0 & 0 & 0 & 0 & 1 & 1 & $\begin{array}{l}\text { Parasitoides de lepidópteros } \\
\text { minadores. }\end{array}$ \\
\hline Opius sp. & 0 & 0 & 0 & 2 & 0 & 2 & $\begin{array}{l}\text { La subfamilia Opiinae incluye } \\
\text { numerosos parasitoides, } \\
\text { frecuentemente, de dípteros } \\
\text { Agromyzidae. }\end{array}$ \\
\hline
\end{tabular}




\begin{tabular}{|c|c|c|c|c|c|c|c|}
\hline \multirow[b]{2}{*}{ Especie } & \multicolumn{6}{|c|}{ Número de individuos por año } & \multirow[b]{2}{*}{ Hospedador } \\
\hline & 2004 & 2005 & 2006 & 2007 & 2008 & Total & \\
\hline Orthotsigma sp.1 & 2 & 0 & 2 & 0 & 1 & 5 & \multirow{2}{*}{$\begin{array}{l}\text { Género con parasitoides de } \\
\text { dípteros Phoridae. }\end{array}$} \\
\hline Orthostigma sp.2 & 0 & 0 & 0 & 0 & 1 & 1 & \\
\hline $\begin{array}{l}\text { Praon exsoletum } \\
\text { (Nees, 1811) }\end{array}$ & 0 & 0 & 2 & 0 & 0 & 2 & $\begin{array}{l}\text { Parasitoides de algunos } \\
\text { hemípteros Aphididae, como } \\
\text { Therioaphis trifolii (Monell, } \\
\text { 1882), en Medicago sativa, etc. }\end{array}$ \\
\hline $\begin{array}{l}\text { Praon } \\
\text { myzophagum } \\
\text { Mackauer, } 1959\end{array}$ & 0 & 0 & 0 & 1 & 0 & 1 & $\begin{array}{l}\text { Parasitoides específicos del } \\
\text { hemíptero Aphididae Myzus } \\
\text { persicae (Sulzer, 1776). Citado } \\
\text { en Citrus sp., sobre } M \text {. persicae. }\end{array}$ \\
\hline Synaldis sp.1 & 0 & 2 & 0 & 4 & 0 & 6 & Numerosos huéspedes. \\
\hline Synaldis sp.2 & 0 & 0 & 2 & 0 & 1 & 3 & $\begin{array}{l}\text { Parasitoides de dípteros } \\
\text { Anthomyiidae, Phoridae y } \\
\text { Platypezidae. }\end{array}$ \\
\hline Triaspis sp. & 0 & 0 & 0 & 1 & 1 & 2 & $\begin{array}{l}\text { Género con parasitoides de } \\
\text { larvas de coleópteros } \\
\text { Curculionidae y Bruchidae. }\end{array}$ \\
\hline
\end{tabular}

\section{Ichneumonidae}

\begin{tabular}{|c|c|c|c|c|c|c|c|}
\hline Aclastus sp. & 0 & 0 & 0 & 0 & 2 & 2 & Endoparasitoides de dípteros. \\
\hline Aneuclis sp. & 0 & 0 & 0 & 0 & 1 & 1 & $\begin{array}{l}\text { Parasitoides del coleóptero } \\
\text { Nitidulidae Meligethes sp. }\end{array}$ \\
\hline Cryptus sp. & 0 & 0 & 0 & 1 & 0 & 1 & $\begin{array}{l}\text { Género con parasitoides sobre } \\
\text { pupas de lepidópteros. }\end{array}$ \\
\hline Cubocephalus sp. & 0 & 0 & 0 & 0 & 1 & 1 & $\begin{array}{l}\text { Parasitoides sobre himenópteros } \\
\text { Tenthredinidae minadores de } \\
\text { tallos. }\end{array}$ \\
\hline Dicaelotus sp.1 & 0 & 0 & 2 & 3 & 3 & 8 & \multirow{3}{*}{$\begin{array}{l}\text { Género con parasitoides de } \\
\text { microlepidópteros. }\end{array}$} \\
\hline Dicaelotus sp.2 & 0 & 0 & 0 & 1 & 0 & 1 & \\
\hline Dicaelotus sp.3 & 0 & 0 & 2 & 0 & 0 & 2 & \\
\hline Dichrogaster sp. & 0 & 2 & 0 & 0 & 0 & 2 & $\begin{array}{l}\text { Parasitoides de pupas de } \\
\text { neurópteros Chrysopidae; citado } \\
\text { sobre Chrysopa carnea Stephens, } \\
1836 .\end{array}$ \\
\hline Diplazon sp.1 & 0 & 0 & 0 & 0 & 1 & 1 & \multirow{2}{*}{$\begin{array}{l}\text { Género con parasitoides de } \\
\text { dípteros Syrphidae. }\end{array}$} \\
\hline Diplazon sp.2 & 0 & 0 & 0 & 1 & 0 & 1 & \\
\hline Eusterinx sp. & 0 & 0 & 0 & 0 & 1 & 1 & Endoparasitoides de dípteros. \\
\hline Exochus sp. & 6 & 0 & 2 & 2 & 2 & 12 & $\begin{array}{l}\text { Numerosos huéspedes. Género } \\
\text { con parasitoides en lepidópteros } \\
\text { Gelechiidae, Tortricidae e } \\
\text { Yponomeutidae. }\end{array}$ \\
\hline
\end{tabular}




\begin{tabular}{|c|c|c|c|c|c|c|c|}
\hline \multirow[b]{2}{*}{ Especie } & \multicolumn{6}{|c|}{ Número de individuos por año } & \multirow[b]{2}{*}{ Hospedador } \\
\hline & 2004 & 2005 & 2006 & 2007 & 2008 & Total & \\
\hline Gelis sp.1 & 0 & 0 & 2 & 0 & 0 & 2 & \multirow{2}{*}{$\begin{array}{l}\text { Huéspedes diversos. Parasitoides } \\
\text { de pupas de lepidópteros } \\
\text { Psychidae, Coelophoridae, pupas } \\
\text { de neurópteros Chrysopidae, y } \\
\text { ovisacos de arácnidos. }\end{array}$} \\
\hline Gelis sp.2 & 0 & 2 & 0 & 2 & 5 & 9 & \\
\hline Hypsicera sp. & 0 & 0 & 0 & 1 & 0 & 1 & Endoparasitoides de dípteros. \\
\hline Megacara sp. & 0 & 0 & 2 & 2 & 3 & 7 & $\begin{array}{l}\text { Numerosos huéspedes. } \\
\text { Parasitoides en pupas pequeñas. } \\
\text { Citados sobre el díptero Musca } \\
\text { domestica L., 1758, el } \\
\text { lepidóptero Plutella xylostella L., } \\
1758 \text { y presente en agallas de } \\
\text { himenópteros Cynipidae, como } \\
\text { Biorhiza y Andricus. }\end{array}$ \\
\hline Oedemopsis sp. & 2 & 0 & 0 & 0 & 0 & 2 & $\begin{array}{l}\text { Parasitoides de varios } \\
\text { lepidópteros, incluidos } \\
\text { Cacoecimorpha pronubana } \\
\text { (Hubner, 1799), Archips Rosana } \\
\text { (L., 1758) y Tortrix viridana L., } \\
\text { 1758. }\end{array}$ \\
\hline Orthocentrus sp.1 & 0 & 0 & 0 & 1 & 1 & 2 & Género con endoparasitoides \\
\hline Orthocentrus sp.2 & 0 & 0 & 4 & 0 & 0 & 4 & $\begin{array}{l}\text { koinobiontes de dípteros } \\
\text { nematóceros, Sciaridae y } \\
\text { Mycetophilidae; a menudo sobre } \\
\text { hongos. }\end{array}$ \\
\hline Phygadeuon sp.1 & 0 & 0 & 1 & 0 & 1 & 2 & Género con parasitoides de pupas \\
\hline Phygadeuon sp.2 & 0 & 0 & 0 & 0 & 2 & 2 & de dípteros braquíceros; también \\
\hline Phygadeuon sp.3 & 2 & 0 & 0 & 0 & 1 & 3 & $\begin{array}{l}\text { hiperparasitoides de lepidópteros, } \\
\text { via Tachinidae. }\end{array}$ \\
\hline Platylabus sp. & 0 & 0 & 0 & 1 & 0 & 1 & $\begin{array}{l}\text { Parasitoides sobre los diversos } \\
\text { lepidópteros, como Eulithis } \\
\text { testata L., 1761, Eupithecia } \\
\text { millefoliata } \text { Rössler, } 1866, \\
\text { Xanthorhoe fluctuata L., } 1758 \text { y } \\
\text { Cabera pusaria L., } 1758 .\end{array}$ \\
\hline Pleolophus sp. & 0 & 0 & 0 & 0 & 1 & 1 & $\begin{array}{l}\text { Parasitoides de lepidópteros } \\
\text { Geometridae. }\end{array}$ \\
\hline Stenomacrus sp.1 & 0 & 0 & 26 & 46 & 0 & 72 & Género con endoparasitoides \\
\hline Stenomacrus sp.2 & 2 & 2 & 0 & 0 & 9 & 13 & $\begin{array}{l}\text { koinobiontes de dípteros } \\
\text { nematóceros, Sciaridae y } \\
\text { Mycetophilidae; a menudo, sobre } \\
\text { hongos. }\end{array}$ \\
\hline
\end{tabular}




\begin{tabular}{|c|c|c|c|c|c|c|c|}
\hline \multirow[b]{2}{*}{ Especie } & \multicolumn{6}{|c|}{ Número de individuos por año } & \multirow[b]{2}{*}{ Hospedador } \\
\hline & 2004 & 2005 & 2006 & 2007 & 2008 & Total & \\
\hline Syrphoctonus sp. & 0 & 0 & 0 & 1 & 0 & 1 & $\begin{array}{l}\text { Parasitoides de dípteros } \\
\text { Syrphidae. }\end{array}$ \\
\hline Trychosis sp. & 0 & 0 & 0 & 0 & 1 & 1 & $\begin{array}{l}\text { Género con parasitoides de } \\
\text { ovisacos de arácnidos. }\end{array}$ \\
\hline Tycherus sp. & 0 & 0 & 0 & 0 & 2 & 2 & $\begin{array}{l}\text { Parasitoides sobre } \\
\text { microlepidópteros. }\end{array}$ \\
\hline Xiphulcus sp. & 4 & 0 & 0 & 1 & 0 & 5 & $\begin{array}{l}\text { Biología diversa. } \\
\text { Ectoparasitoides de pupas o } \\
\text { prepupas de holometábolos; } \\
\text { opcionalmente, endoparasitoides, } \\
\text { koinobiontes o sobre arácnidos. }\end{array}$ \\
\hline Zaglyptus sp. & 0 & 2 & 0 & 1 & 0 & 3 & $\begin{array}{l}\text { Género con ectoparasitoides } \\
\text { gregarios en ovisacos de } \\
\text { arácnidos. }\end{array}$ \\
\hline
\end{tabular}

\section{Platygastridae}

\begin{tabular}{|c|c|c|c|c|c|c|c|}
\hline Amblyaspis sp. & 0 & 9 & 5 & 7 & 9 & 30 & $\begin{array}{l}\text { Parasitoides sobre agallas de } \\
\text { cecidómidos. }\end{array}$ \\
\hline $\begin{array}{l}\text { Amitus spiniferus } \\
\text { Brethes } 1914\end{array}$ & 0 & 9 & 5 & 8 & 6 & 28 & $\begin{array}{l}\text { Parasitoides de la mosca blanca } \\
\text { de los cítricos, el hemíptero } \\
\text { Aleyrodidae Aleurothrixus } \\
\text { floccosus Maskell, } 1896 .\end{array}$ \\
\hline Leptacis sp. & 0 & 0 & 2 & 0 & 0 & 2 & $\begin{array}{l}\text { Parasitoides koinobiontes de } \\
\text { dípteros Cecidomyidae. }\end{array}$ \\
\hline Platygaster sp. & 2 & 0 & 0 & 0 & 1 & 3 & $\begin{array}{l}\text { Género con parasitoides sobre } \\
\text { agallas de dípteros Cecidomyidae. }\end{array}$ \\
\hline Synopeas sp. & 6 & 10 & 2 & 9 & 20 & 47 & $\begin{array}{l}\text { Género con parasitoides sobre } \\
\text { agallas de dípteros Cecidomyidae. }\end{array}$ \\
\hline \multicolumn{8}{|l|}{ Scelionidae } \\
\hline Ceratobaeus sp. & 0 & 0 & 0 & 0 & 1 & 1 & $\begin{array}{l}\text { Posiblemente, parasitoides de } \\
\text { ovisacos de arácnidos. }\end{array}$ \\
\hline Gryon sp. 1 & 0 & 0 & 0 & 1 & 1 & 2 & \multirow{6}{*}{$\begin{array}{l}\text { Parasitoides de hemípteros, } \\
\text { fundamentalmente, Lygaeidae, } \\
\text { Pentatomidae y Reduviidae. }\end{array}$} \\
\hline Gryon sp.2 & 0 & 0 & 0 & 1 & 2 & 3 & \\
\hline Gryon sp.3 & 0 & 0 & 0 & 0 & 1 & 1 & \\
\hline Gryon sp.4 & 0 & 2 & 0 & 8 & 0 & 10 & \\
\hline Gryon sp.5 & 2 & 0 & 2 & 0 & 2 & 6 & \\
\hline Gryon sp.6 & 4 & 2 & 0 & 1 & 2 & 9 & \\
\hline Idris sp. 1 & 0 & 2 & 0 & 0 & 2 & 4 & \multirow{4}{*}{$\begin{array}{l}\text { Género con endoparasitoides en } \\
\text { ovisacos de arácnidos. }\end{array}$} \\
\hline Idris sp. 2 & 0 & 0 & 0 & 0 & 1 & 1 & \\
\hline Idris sp. 3 & 0 & 4 & 2 & 2 & 1 & 9 & \\
\hline Idris sp.4 & 2 & 0 & 0 & 0 & 3 & 5 & \\
\hline
\end{tabular}




\section{Número de individuos por año}

Especie 20042005200620072008 Total

\begin{tabular}{|c|c|c|c|c|c|c|c|}
\hline Telenomus sp. 1 & 0 & 0 & 2 & 0 & 0 & 2 & \multirow{6}{*}{$\begin{array}{l}\text { Género con parasitoides de } \\
\text { huevos de hemípteros y } \\
\text { lepidópteros; también de dípteros } \\
\text { y neurópteros. }\end{array}$} \\
\hline Telenomus sp.2 & 0 & 0 & 6 & 1 & 0 & 7 & \\
\hline Telenomus sp.3 & 0 & 0 & 3 & 48 & 0 & 51 & \\
\hline Telenomus sp.4 & 0 & 0 & 4 & 4 & 0 & 8 & \\
\hline Telenomus sp.5 & 0 & 0 & 8 & 4 & 0 & 12 & \\
\hline Telenomus sp.6 & 70 & 60 & 0 & 0 & 88 & 218 & \\
\hline Trissolcus sp.1 & 0 & 0 & 2 & 13 & 0 & 15 & \multirow{5}{*}{$\begin{array}{l}\text { Género con parasitoides de } \\
\text { huevos de hemípteros; a menudo, } \\
\text { Pentatomoide. }\end{array}$} \\
\hline Trissolcus sp.2 & 0 & 0 & 0 & 6 & 0 & 6 & \\
\hline Trissolcus sp.3 & 72 & 26 & 0 & 0 & 146 & 244 & \\
\hline Trissolcus sp.4 & 0 & 0 & 4 & 7 & 0 & 11 & \\
\hline Trissolcus sp.5 & 0 & 0 & 76 & 54 & 0 & 130 & \\
\hline
\end{tabular}

\section{Diapriidae}

\begin{tabular}{|c|c|c|c|c|c|c|c|}
\hline Coptera sp. & 0 & 0 & 0 & 1 & 0 & 1 & $\begin{array}{l}\text { Endoparasitoides de larvas y } \\
\text { pupas de dípteros. }\end{array}$ \\
\hline Diapria sp. & 4 & 0 & 0 & 0 & 0 & 4 & $\begin{array}{l}\text { Endoparasitoides de larvas y } \\
\text { pupas de dípteros. }\end{array}$ \\
\hline Entomacis sp. & 2 & 2 & 0 & 1 & 0 & 5 & $\begin{array}{l}\text { Endoparasitoides de larvas y } \\
\text { pupas de dípteros, a menudo, en } \\
\text { ambientes húmedos. }\end{array}$ \\
\hline Pantoclis sp. & 0 & 0 & 3 & 0 & 0 & 3 & $\begin{array}{l}\text { Endoparasitoides de larvas y } \\
\text { pupas de dípteros. }\end{array}$ \\
\hline Trichopria sp.1 & 0 & 0 & 2 & 0 & 0 & 2 & \multirow{3}{*}{$\begin{array}{l}\text { Endoparasitoides de larvas y } \\
\text { pupas de dípteros, a menudo, en } \\
\text { ambientes húmedos. }\end{array}$} \\
\hline Trichopria sp.2 & 0 & 0 & 0 & 5 & 1 & 6 & \\
\hline Trichopria sp.3 & 0 & 0 & 0 & 1 & 3 & 4 & \\
\hline
\end{tabular}

\section{Proctotrupidae}

$\begin{array}{llllllll}\text { Exallonyx sp. } & 2 & 0 & 0 & 0 & 0 & 2 & \text { Género con parasitoides sobre }\end{array}$ larvas de coleópteros

Staphylinidae, rara vez sobre Carabidae. 